VOL. 7

JUNE, 1932

No. 1

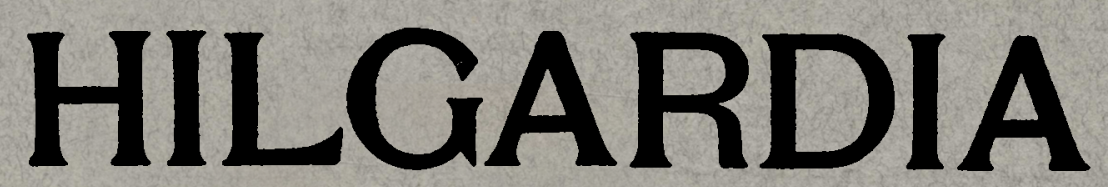

A Journal of Agricultural Science PUBLISHED BY THB

California Agricultural Experiment Station

CONTENTS

Variations in Citrus Seedlings and Their Relation to Rootstock Selection

H. J. WEBBER

UNIVERSITY OF CALIFORNIA PRINTING OFFICE BERKELEY, CALIFORNIA 
The titles of the Technical Papers of the Callformia Agricultural Experiment station, which HIICAARDIA replaces, and coples of which may be had on application to the Publications Secretary, Agricultural Experiment 8tation, Berkeley, are as follows:

4. Effect of Sodium Chlorid and Calcium Chlorld upon Growth and Composdtion of Young Orange Trees, by H. S. Reed and A. R. C. Haas April, 1923.

E. Citrus Blast and Black Pit, by H. 8. Fawcett, W. T. Horne, and A. F. Camp. May, 1923.

6. A Study of Declduotus Fruit Tree Rootstocks with Special Reference to Their Identification, by Myer J. Heppner. June, 1923.

7. A Study of the Darkening of Apple Tissue, by E. I. Overholser and W. V. Cruess. June, 1923.

8. Effect of Salts on the Intake of Inorganic Elements and on the Buffer System of the Plant, by D. R. Hoagland and J. C. Martin. July, 1923.

Q. Experiments on the Reclamation of Alkall Boils by Leaching with Water and Gypsum, by P. L. Hibbard. August, 1923.

10. The Seasonal Variation of the soll Moisture in a Walnut Grove in Relation to the Hygroscopic Coefflcient, by L. D. Batchelor and H. 8. Roed. September, 1823.

11. Studies on the Effects of Sodium, Potassium, and Calcium on Young Orange Trees, by H. S. Reed and A. R. C. Haas. October, 1923.

12. The Effect of the Plant on the Reaction of the Culture solution, by D. R. Hoagland. November, 1923.

14. The Respiration of Potato Tubers in Relation to the Occurrence of Blackheart, by J. P. Bennett and E. T. Bartholomew. January, 1924.

16. The Moisture Equivalent as Influenced by the Amount of Soll Used in its Determination, by F. J. Veihmeyer, O. W. Israelsen and J. P. Conrad. September, 1924.

17. Nutrient and Toxdc Effocts of Certain Tons on Citrus and Walnut Trees with Especial Beference to the Concentration and $\mathrm{Ph}$ of the Medium, by H. 8. Reed and A. R. C. Haas. October, 1924.

18. Factors Influencing the Rate of Germination of the Seed of Asparagus Offlelnalis, by H. A. Borthwick. March, 1925.

19. The Relation of the Subcutaneous Administration of Living Bacterfum Abortum to the Immunity and Carrier Problem of Bovine Infectious Abortion, by George H. Hart and Jacob Traum. April, 1925.

20. A Study of the Conductive Tissues in Shoots of the Bartlett Pear and the Relationship of Food Movement to Dominance of the Apical Buds, by Frank E. Gardner. April, 1925. 


\title{
HILGARDIA
}

\author{
A JOURNAL OF AGRICULTURAL SCIENCE \\ PUBLISHED BY THE
}

CALIFORNIA AGRICULTURAL EXPERIMENT STATION

Vol. 7

JUNE, 1932

No. 1

\section{VARIATIONS IN CITRUS SEEDLINGS AND THEIR RELATION TO ROOTSTOCK SELECTION ${ }^{1,2}$}

\author{
H. J. WEBBER 3
}

CONTENTS

PAGE

Introduction

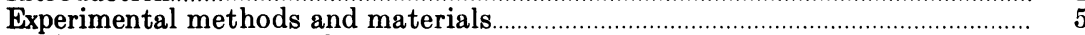

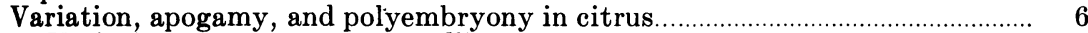

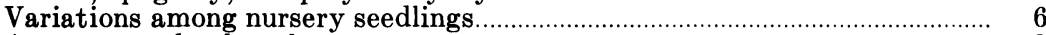

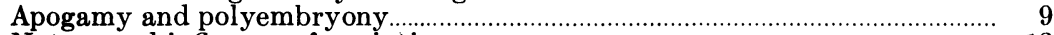

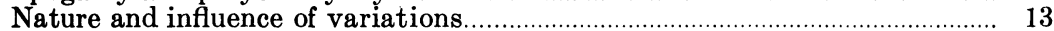

Tests of large, medium, and small nursery trees on sweet-orange stocks.......... 15

Reaction on scions caused by different-sized rootstock seedling.......................... 23

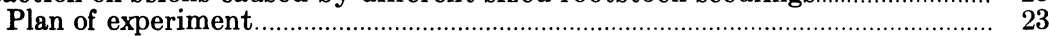

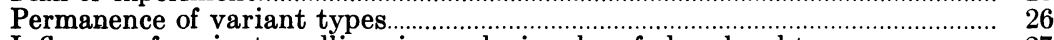

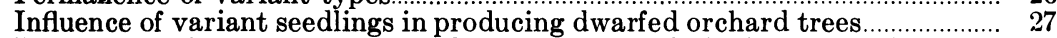

Influence of size of rootstock seedlings on size and yield of orchard trees.... 34

Relation of size of budlings to size of 8-year-old orchard trees, as shown by trunk area

Relation of size of budlings to size of 8-year-old orchard trees, as shown by top volume

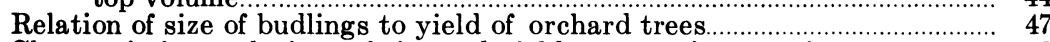

Changes in interrelations of size and yield as trees increase in age................ 48

Suggestive results from this experiment.................................................. $\quad 50$

Effect of budling size on the size and yield of orchard trees in a selected population on sweet-orange stocks...

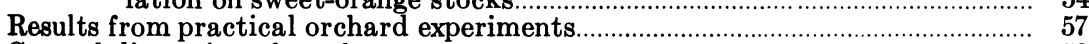

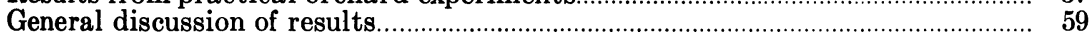

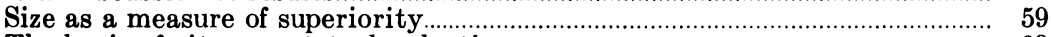

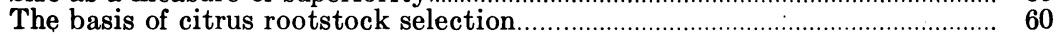

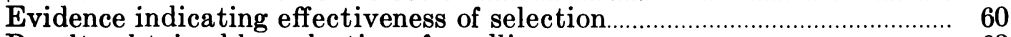

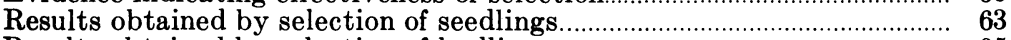

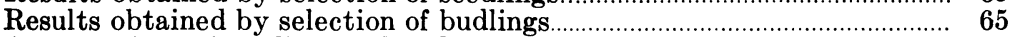

A comparison of seedling and budling selection........................................ $\quad 66$

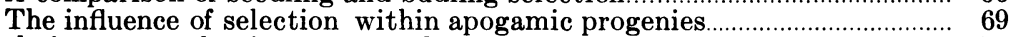

Method of nursery selection suggested......................................................... 71

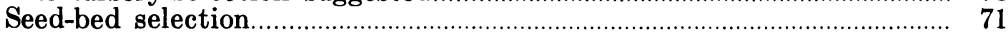

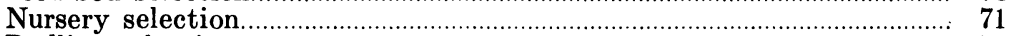

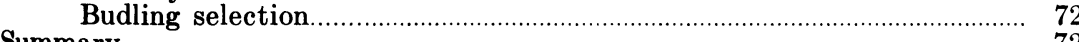

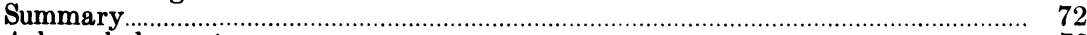

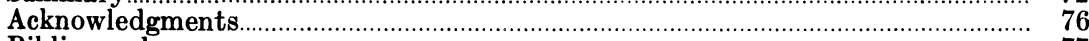

Bibliography

1 Received for publication May 3, 1932.

2 Paper No. 263, University of California Graduate School of Tropical Agriculture and Citrus Experiment Station, Riverside, California.

3 Professor of Subtropical Horticulture in the Experiment Station. 


\section{IN'TRODUCTION}

Although the question of securing the best rootstocks to use in citrus propagation has for many years attracted the attention of growers, experimentation on the subject has been very limited. The earliest general publication on citrus stocks in America, that of Van Deman (1891), is a summary of the observations and studies made on groves in Florida and is not based on comparative experiments. Mills (1902) has described the results of certain experiments conducted by the California Experiment Station at Pomona, California ; and Bonns and Mertz (1916), the results of a series of comparative experiments made at the Citrus Experiment Station at Riverside.

A carefully planned and executed experiment was also carried out for a limited time by Taber (1904) at Glen St. Mary, Florida, with certain varieties propagated on Trifoliate orange, sour orange, and sweet orange. The experiment was designed primarily to determine the comparative value of the cold-resistant Trifoliate orange as a stock.

As a result of these studies and experiments and of the cumulative understanding of growers derived from long experience, certain stocks have come to be commonly used, and success in general has been achieved with them. It is well recognized, however, that the problems connected with rootstocks are poorly understood, and there is little evidence to justify a conclusion that the species and varieties now used as stocks are the best available. A fair appreciation of the value of sour orange, sweet orange, lemon, grapefruit, and certain other species as stocks has been acquired, but until recently no attention has been directed to variations within these species and the influence of such variations on the fruit or scion variety. Until recently this was also the case in the propagation of all other commercial fruits, such as the apple and pear.

The experiments herein reported, which were started in 1914 (Webber, 1919 and 1920), resulted in directing attention to the great variability among seedlings of the same species or stock type, and to the probable influence of such variation on the uniformity of the orchard trees produced. The present paper will outline the results obtained with these experiments up to the present time, and will discuss briefly the influence that the findings may have in improving nursery methods in the future. 
It has been claimed for certain fruits, such as the apple (Swarbrick and Roberts, 1927 ; and Roberts, 1929), that the scion variety dominates the scion-stock combination, determining the character and form of the root produced. It is to be regretted that no thorough study of this point has as yet been made with citrus, owing largely to the almost universal practice of "balling" nursery trees in transplanting, a practice which does not permit an examination of the roots. In such trees as have been examined nothing has been observed to indicate that the scion has any material effect in changing the characteristic branching of the root, whether budded low or high. As an illustration, the examination of a considerable number of orchard trees of all ages from 6 to 75 years, that has been made from time to time, has shown conclusively that the tendency of the sour orange to form a distinct taproot is not visibly modified by the scion variety; and that the sweet orange, which normally shows a weak taproot development, exhibits this character when used as a stock, regardless of the scion variety. Of course it is true that some other scion variety than those observed might exert a profound influence on the stock, and careful studies may show influences that are not now suspected.

The writer's observations, though limited in extent, apparently confirm the results obtained by Amos, Hatton, Hoblyn, and Knight (1930), and Vyvyan (1930) in their studies of the effect of scion on root in apples, where the roots of the stock type were found to retain their characteristic branching regardless of the scion variety used or the height of the insertion of the scion. The size of the root, however, was distinctly influenced, and this is also the case with citrus.

The writer has observed numerous cases where the size of the root system was doubled or quadrupled by the reaction of different scions. Very remarkable influences of this sort have also been recorded in several stionic combinations in citrus by Brown (1920) in India.

Recently in experiments with the Trifoliate orange used as a stock with various orange, mandarin, lemon, and grapefruit varieties, Tanaka (1931) has described certain influences on the stock caused by the scion variety. He states "Generally speaking the subterranean part of sweet-orange top is deep rooted (branches narrow angled), while that of lemon top is shallow rooted (branches broad angled). The color of Trifoliate root used for the lemon stock shows lighter coloration than when other scions are employed for the top."

The evidence presented in this paper also points to the conclusion that the size and vigor of the orchard tree is considerably influenced 
by the character of the seedling used as a stock, and apparently justifies the adoption of some method of stock selection.

That more complex influences also occur is shown by the reaction on the normal soluble magnesium content in the ash of the bark of the stock as effected by that of the scion. Citrus species differ in the normal magnesium content in the bark, and a normally high-magnesiumcontent scion has been shown to increase that of a low-content stock, while a normal low-magnesium content of the scion type tends to depress that of a high-content stock (Haas and Halma, 1929).

The writer's studies and experiments have revealed many cases where there is a mutual influence between the stock and scion. It is clear that these influences require study to determine the extent of the influence for each variety and stock combination, in order that orchards may be planned on a safe and sure foundation.

The influence of the stock on the scion, and vice versa, may in general be considered as similar to an environmental reaction. Each of the two distinct portions of the tree retains its individual or genetic characteristics, but these may be modified in expression by the changed stionic conditions, much as they might be modified by a change of environment. These changes are usually quantitative variations such as changes in size of plant or fruit, size of crop, longevity, and density of color. The characters that are changed by the reactions between stock and scion, for simplicity of expression are here designated as stionic variations or stionic reactions. ${ }^{4}$

The present paper deals mainly with the stionic reactions caused by the use of seedling stocks of the same species but of different sizes and types. An attempt is made to answer the following questions: (1) Do all seedlings of the same species or even of the same variety, when budded with the same fruit variety, produce orchard trees of standard size and character? (2) If not, is there any means of segregating the good seedlings from the bad?

4 For the sake of clarity and brevity in this discussion, several new words coined by the writer are introduced, which require explanation:

Stion-any plant or tree composed of a stock and scion growing in combination. This term is used regardless of the method employed in propagation, i.e., budding, grafting, inarching, etc. It is formed by combining the first two letters of the word stock with the last three letters of scion.

Stionic-pertaining to a stion.

Stionio variation-a variation eaused by the reaction between stock and scion. Budling - a young, budded nursery tree. 


\section{EXPERIMENTAL METHODS AND MATERIALS}

In the several experiments to be reported here, care was used to treat the plants in each experiment as uniformly as possible in order to reduce the variation to a minimum, except as caused by the different stocks used.

Considerable doubt existed in the beginning as to what records should be made that would best indicate tree size at various stages of growth. The size measurements of the seedlings used were diameter or circumference of trunk taken 3 to 4 inches above the ground, and the greatest height attained by the plant. No feasible method of measuring the top volume of a small seedling was found. It may be worthy of note here that it has since been regretted that the weight of the top of each seedling was not recorded when the top was cut off to force the bud, for such weights would probably have been very accurate indicators of the comparative size of the nursery trees.

The same measurements which were taken for the seedlings were also taken for the budlings, namely, diameter or circumference of trunk, and maximum height. The diameter or circumference of the stock was taken at the smallest point between the soil and the bud union, and that of the scion trunk at a point 2 inches above the bud, unless otherwise stated. These measurements of the budded nursery trees were made in the early spring immediately preceding the transplanting of the budlings to the orchard, and were thus the measurements for the 1-year-old nursery trees. The height measurements of citrus nursery trees, whether of the seedlings or of the budlings, have been found in most cases to be a very poor indicator of size and thus have not been used in this paper.

The size and vigor of the orchard trees were judged by trunk size as indicated by circumference measurements, volume of top, and total yields of fruit. The trunk size was determined by circumference measurements of the stock trunk at the smallest point between the soil and the bud union, and that of the scion trunk by circumference measurements at a point between 4 and 6 inches above the bud union. The top volume was determined by the use of a fumigation tent placed over the tree; the measurements were carefully recorded and the volume obtained by the Woglum formula (Woglum, 1909, p. 25). The yield of each tree under experiment is determined by weighing the fruit in the field and is recorded each year in pounds per tree. 
In the statistical calculations, area of trunk cross section is used rather than diameter or circumference, and is of course obtained from the diameter or circumference records. Such measurements have been taken uniformly in centimeters and square centimeters, while volume measurements have been taken in cubic feet, and the yields in pounds. As all students are familiar with both systems of weights and measures, it has not seemed worth while to transpose the figures into a uniform system.

In the discussion presented here the nomenclature used is that prevalent in citrus sections of the United States and is based on that given by W. T. Swingle in Bailey's Standard Cyclopedia of Horticulture. The common names of the species are used mostly and if a special variety is used its generally recognized name is given. The following are the principal common names used with their equivalent botanical names : sweet orange (Citrus sinensis Osbeck); sour orange (C. aurantium Linn.) ; grapefruit (C. maxima Merrill) ; Rough lemon (variety of $C$. limonia Osbeck); Trifoliate orange (Poncirus trifoliata Raf.).

\section{VARIATION, APOGAMY, AND POLYEMBRYONY IN CITRUS}

Before proceeding to the discussion of the experiments it will probably clarify the problems involved to discuss the nature of the variation occurring among citrus seedlings and the influence that is introduced by the very general occurrence of the phenomena of apogamy and polyembryony.

\section{Variations Among Nursery Seedlings}

During the last 40 years, the sour orange has been more extensively used as a rootstock in California, Florida, and Mediterranean countries than any other Citrus species, and therefore, the study of variations in the seedlings of this species is of particular interest from the stock standpoint. In 1915, at an early stage in the present investigations, the examination of a commercial nursery near Whittier, California, of sour-orange seedlings which were of the size and age for budding revealed the presence of what appeared to be a considerable number of different types. All apparently were sour-orange seedlings but certain individuals exhibited different characters of size, foliage, branching, and general habit from the prevailing and apparently normal type exhibited by the other seedlings in the same 
nursery. About 25 different seedlings that seemed to vary in some morphological character from the general type were chosen for study, and buds were taken from each to propagate and test the type. At the same time one particularly large and vigorous seedling of an apparently normal type was also selected for comparison. Two trees of each of the types chosen were propagated on Rough-lemon stocks. The budlings of these were grown at the Citrus Experiment Station and in the spring of 1917 were planted in a row in the experimental orchard (field I, block A, row 16) adjacent to the experimental rows of large, medium, and small trees described in the following section.

The trees propagated from these variant ${ }^{5}$ seedlings which in the nursery had not appeared to be very widely different from each other or from the normal type of the sour orange, as they grew older exhibited markedly different characters in size, branching, foliage, and fruits. The trees are now 15 years old (17 years from the bud) and they still retain in equal degree their characteristic differences as described in earlier publications (Webber, 1920 and 1920a). Several of the trees are veritable dwarfs, the tops at 15 years of age being only about 4 feet high, densely branched, and "scrubby" in appearance, while others are of various sizes up to nearly standard (fig. 1). Some were so weak and aberrant that they lived a few months only. The seedling that was chosen as representing what appeared to be a good standard of the prevailing or normal type in the nursery was propagated and grown along with the others. It proved to be a vigorous grower and is to be considered as representing an excellent strain of the sour orange. ${ }^{6}$

The range of differences in branching, foliage, and fruit characters exhibited by the trees propagated from these variant seedlings is in some cases as great as that found between diverse species of Citrus, and yet all were taken from one comparatively small sour-orange nursery and were apparently direct derivatives from the sour orange.

The examination of other orange nurseries in various parts of the state demonstrated the fact that similar variations among the seedlings occurred commonly. The variations were present in about equal numbers in every sour-orange nursery examined and what appeared to be

\footnotetext{
5 The term "variant" is used here to designate any seedling that is different from the normal or ordinary type in a certain progeny, in any easily recognizable character.

6 In later experiments, seedlings from one tree of this strain or clon have been used as representing a selected standard strain of the sour orange. "Standard" has become a varietal name for this clon of the sour orange, as a result of the continuous use of the term.
} 


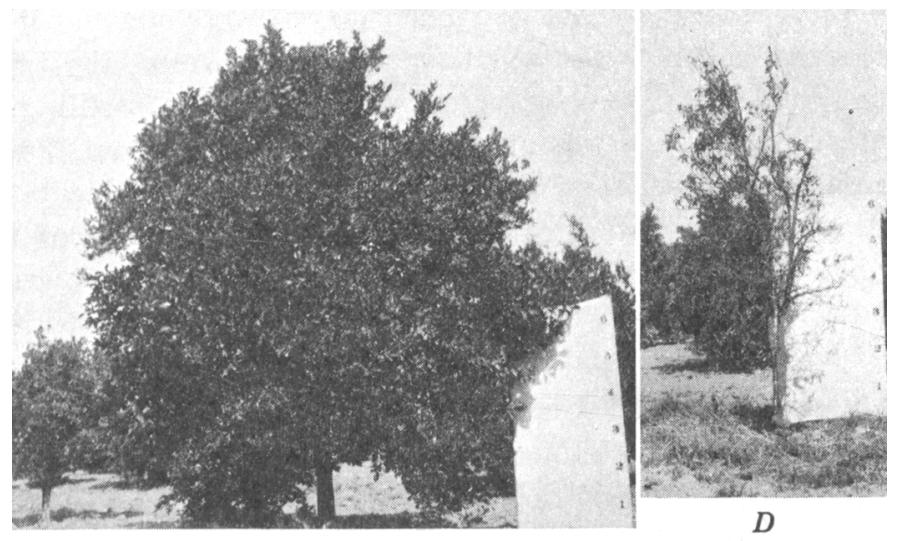

$A$

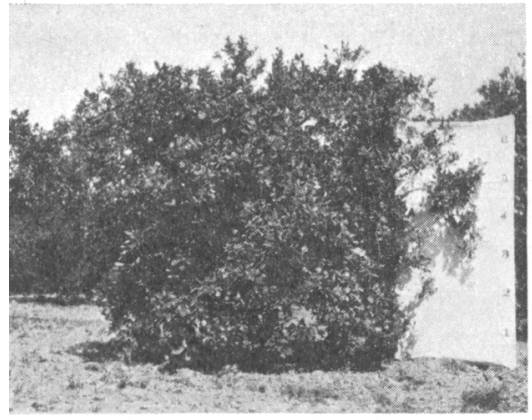

$B$

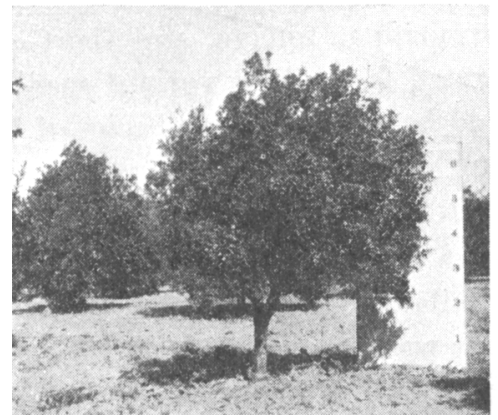

C

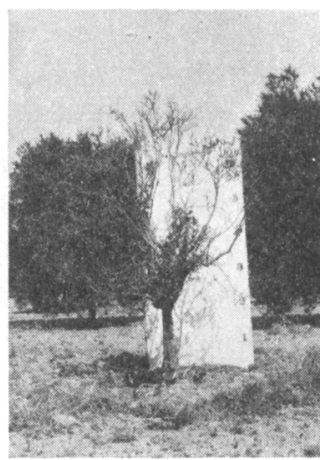

$E$

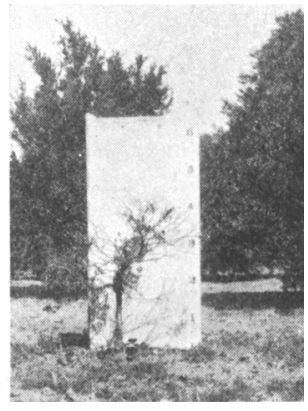

$F$

Fig. 1. Types of sour orange propagated from variant seedlings found in nursery at Whittier, California. $A$, selected normal type, the standard; $B$, medium large size, spreading top; $C$, medium size, no oil glands; $D$, erect columnar top, long narrow leaves; $E$, small weak type; $F$, extreme dwarf but st:ll living. All are 15 years old from date of setting in orchard and are on Rough-lemon stocks. 
similar variants were also found among nursery seedlings of the sweet orange, grapefruit, and Rough lemon.

In most nurseries, at the time these preliminary observations were being made, such seedlings as were deemed too small when the first budding was done were left and budded later when they had reached the proper size. Budlings that were too small when the main lot was dug and sold were held an extra year or more until they reached salable size. Could it be that these small seedlings, which apparently are mainly variants, would produce equally good orchard trees when budded with good standard fruit varieties, or might it be that the poorly growing trees that were to be found in many orchards were inadvertently propagated on such variant seedling stocks? No experiments had been made to determine what influence such variant types of seedlings had on the scion, and this was evidently an important point to determine. Experimental data obtained from tests of such seedlings will be given in a later section of this paper.

\section{Apogamy and Pol yembryony}

Of even greater importance than the occurrence of these variants was the fact that a large proportion of the seedlings grown in any nursery from seed derived from the same source, presented a prevailing dominant type that was usually exhibited by from 60 to 90 per cent of the total population. The occurrence of this dominant type in such a large proportion of the seedlings is evidently due to the prevalence of apogamic reproduction in the various Citrus species and varieties.

In the great majority of plants, seed production is from necessity preceded by the pollination of the stigma followed by the fecundation of the single egg cell and the development of a single embryo from the egg cell. The various species and varieties of citrus, however, have evolved the ability, through means of the phenomenon termed "apogamy," to produce viable embryos in the seed which have no direct relation to the regular egg apparatus and fecundation.

According to the investigations of Strasburger (1878) and Osawa (1912), this is accomplished by the specialization of certain cells or groups of cells in the body of the ovary (nucellus) of the mother near the wall of the embryo sac. These cells become highly protoplasmic,

7 "Apogamy" is used here in its general sense as referring to the production of embryos in the seed without fecundation, from diploid cells of the mother plant. Reproduction through such embryos is equivalent to vegetative propagation and gives rise to clons, the individuals of which are genetically homogeneous. 
grow and divide more rapidly than the neighboring cells, and finally form masses of tissue which push out into the embryo sac and form embryos so nearly like those which develop from the egg cells proper that the two types of embryos cannot be distinguished one from the other in the seed.

Since the apogamic embryos originate from the somatic tissue of the mother and are not preceded by a reducing division and fecundation, they naturally carry the full diploid chromosome complement direct from the mother and transmit the same heritage as the mother type. It would be expected, therefore, that they would reproduce seedlings of the same type as the mother unless some irregularity occurs in an occasional cell division, and such irregularities are not common.

While the ovaries of citrus contain (except very rarely) only one egg cell each, and thus one sexually developed embryo, this apogamic development commonly leads to the formation of several embryos (usually from 2 to 4 and occasionally as high as 10 or 12) in each seed (polyembryony). All of these are somatic in origin except that one which comes from the egg cell following fecundation. It is also an important phenomenon that apparently this one sexual embryo frequently fails to develop, owing to lack of fecundation, crowding, or some other cause, in which case all of the embryos of a seed are apogamic.

In 1900 Webber pointed out the difficulties that this phenomenon introduces into the study of citrus hybrids, where a large percentage of the seedlings that develop from carefully crossed and guarded flowers are of apogamic origin. The seedlings from apogamic embryos cannot be distinguished readily in early stages from the true hybrids unless the parents differed markedly in some character which, combined in the hybrid, results in some distinctive character of foliage that would enable the hybrids to be recognized. In hybrids of parents with similar foliage and plant-body characters the true hybrids cannot be distinguished with certainty until they bear fruit, thus necessitating the expense of growing large numbers to secure a few hybrids. Here apogamy is a distinct disadvantage.

In citrus culture the main influence of apogamy is likely to be found in its relation to the problem of securing rootstocks of uniform character. During the last 10 years attention has been focused on the very great importance of the character of the rootstocks used in horticultural propagations. It has become increasingly evident that the genetic variation in seedlings used as stocks is to be considered 
responsible for much of the variation in tree size and production exhibited in orchards. Therefore, in the propagation of citrus, as is the case with other orchard fruits, the great desideratum is the availability of rootstocks that are known to possess the same heritage and to react similarly under the same environmental conditions with a given scion variety.

To obtain such uniform rootstocks, experimentation has been directed toward vegetative propagation, through cuttings or layers of known types of stocks and the comparison of the results produced by stocks thus obtained with the results obtained when the more or less variable seedlings from the same type are used. This work, mainly introduced and stimulated through the investigations of Hatton and his coworkers (1917 and later) on the vegetative propagation of deciduous fruit stocks, has been taken up recently by many American experiment stations.

In the studies of citrus rootstocks which are being conducted by the writer, it was soon recognized that apogamy was likely to exercise an important rôle, as it was known that several of the stocks commonly used exhibited a high degree of apogamic development. The early studies of Webber (1900 and 1900a) and the more recent investigations of Frost (1926) and of Toxopeus (1930) have indicated that the variation in the percentage of apogamic embryos in some of the Citrus species and varieties commonly used as stocks is approximately as follows: sweet orange (C. sinensis), from 40 to 95 per cent; sour orange (C. aurantium), 75 to 85 per cent $;^{8}$ grapefruit (C. maxima), 60 to 95 per cent; mandarin orange (C. nobilis), 10 to 100 per cent; lemon (C. limonium), 10 to 96 per cent; citron ( $C$. medica), 40 to 50 per cent; and Trifoliate orange (Poncirus trifoliata), 72 per cent. This wide variation in the percentage of apogamy shown by different species, and by different varieties or races of the same species it would seem must be of significance in the production of uniform progeny, and thus in the adaptability of the different sorts for use as stocks.

A factor of exceptional interest in this connection is the high percentage of apogamy exhibited by some $\mathrm{F}_{1}$ hybrids of radically distinct species, and the fact that such hybrids frequently are exceptionally vigorous and likely to possess value as stocks. As an illustration the Trifoliate orange crossed with the sweet orange gave rise to the group

8 The percentage of apogamy given for the sour orange is based on the count of variants observed in seedling progenies, and not on counts of recognizable hybrids produced through the use of protected flowers crossed with carefully chosen male parents, as is the case for the other estimates given. 
of $\mathrm{F}_{1}$ hybrids which have been designated "citranges" (Webber and Swingle, 1904). Some of these have already attracted attention as desirable stock types. Progenies of several hundred plants of each of several of these hybrid varieties, namely, Savage, Cunningham, Morton, Coleman, and Rusk, have been grown in connection with the writer's experiments and found on careful examination of 3-year-old seedlings to have reproduced apparently true to the variety type $\left(F_{1}\right.$ hybrid $)$ in all cases. The seedlings of these varieties, therefore, are to be considered as approximately 100 per cent apogamic. However, attention should be called to the fact that in the writer's experiments, one of these citranges (the Sanford) apparently develops few if any apogamic embryos and has been found to break up into many types in the $\mathrm{F}_{2}$ generation.

A high percentage of apogamy is also exhibited by the Sampson tangelo (grapefruit $q \mathrm{X}$ tangerine $\delta^{\top}$ ), where the $\mathrm{F}_{2}$ seedlings produce trees of the same character as the original $F_{1}$ hybrid. Twenty-eight $F_{2}$ seedlings of the Sampson tangelo, chosen merely as the most vigorous among a progeny of approximately 100 plants, were planted at an age of about 2 years in the variety orchard of the Citrus Experiment Station in 1917. They are now about 16 years old and are adjacent to several budded trees of the $F_{1}$ hybrid variety, thus affording opportunity for an easy comparison of their characters with those of the mother type. The $\mathrm{F}_{2}$ seedlings are remarkable for the uniformity they exhibit among themselves in size, branch, foliage, and fruit characters, and for their vigorous growth. They can be distinguished from the $\mathrm{F}_{1}$ budded trees only by their more upright growth, which is a character almost invariably exhibited by seedlings as distinct from budded trees.

The examination of a population of over 200 Sampson tangelo 2-year-old $\mathrm{F}_{2}$ seedlings also showed only typical foliage characters of the variety $\left(F_{1}\right.$ hybrid characters). Thus it is clear that the seedlings of the Sampson tangelo are approximately 100 per cent apogamic under ordinary conditions.

From the high percentage of apogamy occurring in such a wide range of Citrus species and varieties, it seems clear that the obtaining of satisfactory stock types that produce seedlings of uniform genetic constitution should present little difficulty, although in most cases a small number of sexually produced embryos develop seedlings. 


\section{Nature AND INFLuence OF VARIATIONS}

It has been found that among the progenies of all species and varieties not completely apogamic, there occurs a small proportion of seedlings that differ from the prevailing type of the progeny in character of branching, foliage, and fruit. Most commonly these variants, which are described in the early part of this section, page 7 , are comparatively small in size, though some are nearly normal, and it has been shown in experiments described later in this paper that almost invariably they produce some degree of dwarfing in the scions grown on them.

The evidence available indicates that these variants apparently are seedlings produced from the normal (sexual) embryos. It may be that some of these variants come from apogamic embryos and are produced by gene mutation, or by chromosome aberration in the somatic tissue. It is probable, however, that the great majority of them are to be considered as coming from the sexual embryos. Of this majority, an occasional variant seems to be a hybrid produced by cross-fertilization, and mutation may occasionally be concerned, but segregation following self-fertilization seems to be the most probable explanation in most cases. The very general interfertility of Citrus species and varieties favors wide natural crossing, and the abundant production of apogamic embryos favors the long persistence of heterozygosis produced by crossing and the gradual increase in the number of heterozygous factors by the accumulation of recessive mutations. The lack of vigor of most of the variants suggests the presence of recessive genes.

Frost (1926, p. 388) states "Selfing probably produces, as a rule, fewer and weaker viable sexual progeny than does crossing. .... Probably most of the undesirable variant types among nursery seedlings are produced by fertilization. . . . . From this point of view, clons which produce seed with fairly numerous embryos are likely to give better results (for stocks) than clons usually with monembryonic seeds. The suitability of the Florida Rough lemon for use as a stock, plainly depends partially on the fact that it is highly polyembryonic and therefore unlike the Lisbon lemon, reproduces mainly by apogamy when selfed."

The elimination of the variants from a batch of nursery seedlings before they are budded (as will be shown later) is apparently the most important selection that can be made in the nursery. The seed- 
lings remaining after such an elimination, if from the same mother tree or clon, can be safely considered to be chiefly of apogamic origin and of nearly uniform genetic constitution. Such seedlings should possess the same degree of congeniality with the scions of any given fruit variety worked on them by budding or grafting; and the reactions produced under a given set of conditions can be determined with sufficient accuracy so that apparently the same result can be expected to follow whenever the same combinations are used under the same set of conditions.

Probably no such certainty of results could ever be obtained by the use of variable seedlings of differing genetic constitution, such as those obtained from cross-pollinated plants that develop seeds in the normal way from the fertilized egg cells only. Apogamy thus apparently furnishes the citrus nurserymen with a means of obtaining easily from any known good stock type, large batches of seedlings that can be depended upon to be of nearly uniform genetic type and to give a uniform reaction on the scion. This result has apparently been of great value to the industry in the past, although not generally recognized, and is likely to be of even greater importance in the future as more is learned about the conditions and the reactions to be expected.

Seedlings of all citrus species (whether of apogamic origin or developed from egg cells in the normal way) are, of course, subject to the same environmental influences as are other plants, and show the same general classes of variation. Developmental or environmental variations are of course shown by both types of citrus seedlings, and the extent and influence of such variations in seedling progenies will be discussed later. Mendelian or genetic variations are exhibited in seedlings from the sexually produced embryos, but should not show in the apogamic seedlings, which supposedly are of uniform genetic constitution. Mutations are likely to occur among seedlings from either of the two types of embryos, but are not common. In the discussions in this paper they probably would be classed merely as variants and eliminated as such. In the following discussions of populations grown in connection with different experiments, it should be remembered that the seedlings continually referred to as variants are those which probably have come from the sexual embryos in most cases. The different characters exhibited by them are probably to be considered as Mendelian or genetic variations. Some of these variants may be mutations, but this could not be determined without extended investigations. 
After the exclusion of the variants, the remaining population (referred to as "entire population without variants") is to be considered as seedlings from apogamic embryos that possess the same genetic constitution as the mother parents from which the seed came. As the seeds in these experiments were not taken from single trees, there may be some variation in the genetic constitution of these populations even after all variants are eliminated.

\section{TESTS OF LARGE, MEDIUM, AND SMALL NURSERY TREES ON SWEET-ORANGE STOCKS ${ }^{9}$}

In a nursery planted in 1914, and intended to supply some 5,000 trees to be used in starting a fertilizer experiment at the Citrus Experiment Station of the University of California, greater than ordinary uniformity among the trees was desired, and much care was thus taken in the growing and handling of the nursery (see Batchelor, Parker, and McBride, 1928). The seed used in growing the rootstocks was taken from four old seedling trees in the grove of R. S. Thompson at Highlands, California, and these four trees were from seed taken from sweet oranges from Tahiti and planted in 1886 .

When the seed bed was dug the small seedlings were discarded to the extent of about 10 per cent of the whole number. The others were planted in the nursery, handled as uniformly as possible, and, with the exception of small, deformed, or apparently "off-type" seedlings, were budded at the same time with buds from highly selected trees. When the budlings had reached the age to be transplanted into the orchard they presented the appearance of an exceptionally fine block of very uniform nursery trees; and yet, when the selection of trees was made to plant the experiment in question, it was found that the sizes of the scions, 3 to 4 inches above the bud union, varied from 0.85 $\mathrm{cm}$ to $3.00 \mathrm{~cm}$ or more in diameter. ${ }^{10}$

In order to obtain some clue as to what would have been the result if all sizes of the nursery trees had been used without selection, a comparative trial was planted with 18 large, 18 medium, and 18 small trees of each of three varieties: Washington Navel orange, Valencia orange, and Marsh grapefruit, all on sweet-orange stocks, a total of

9 For earlier reports on this experiment, with photographs showing the comparative size of the trees, etc., see Webber (1919, 1920, and 1920a).

10 The selected budlings from this nursery that were planted in the fertilizer experiment referred to have furnished some interesting data that is summarized on page 54 of this paper. 


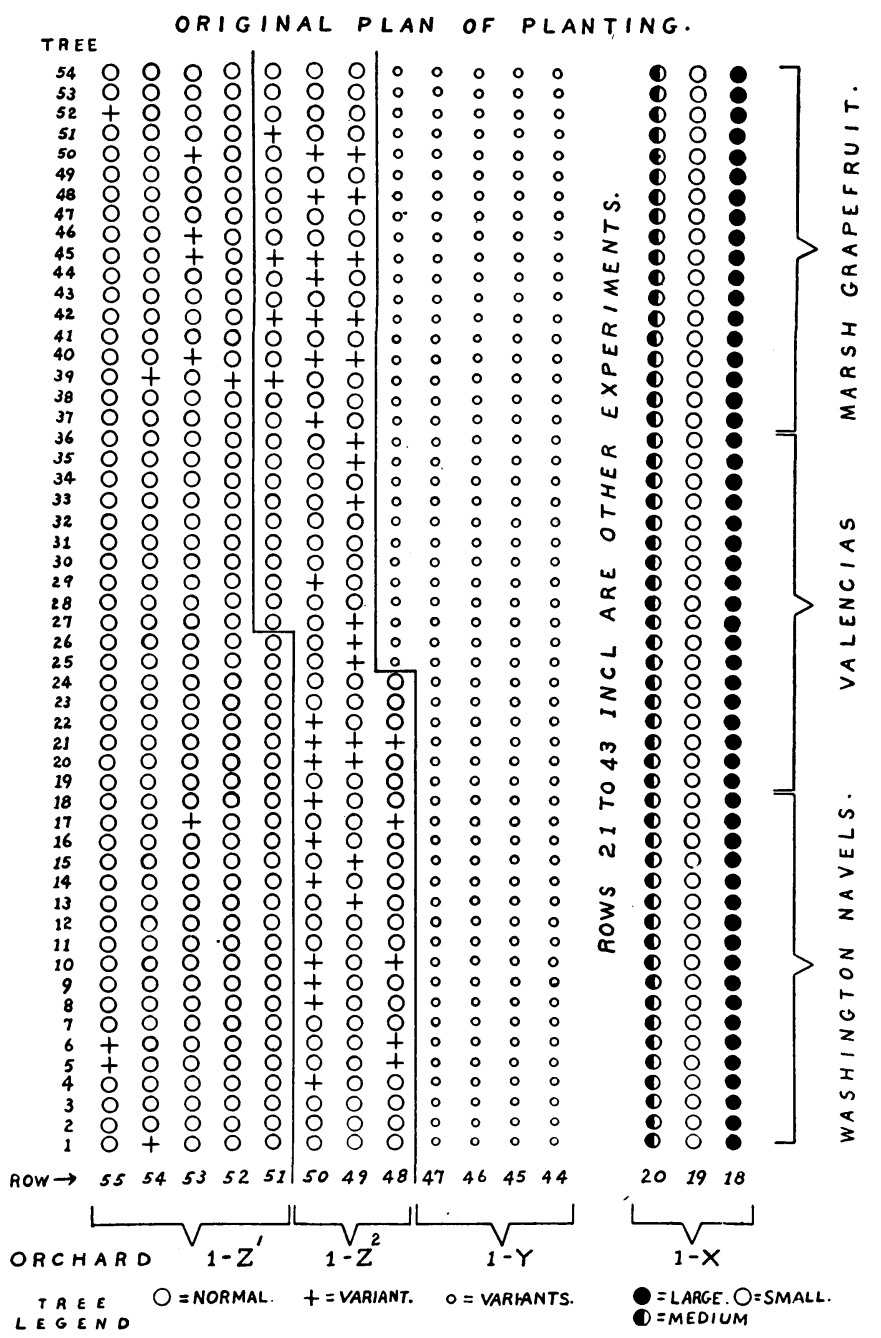

Fig. 2. Outline plan of experimental orchards, the results from which are discussed in this paper. All in field 1, blocks A, B, and C, Citrus Experiment Station, Riverside, California.

1-X: Rows 18-20. Tests of large, medium, and small budlings of Washington Navel and Valencia oranges and Marsh grapefruit. All on sweet-orange stocks. Planted in 1917.

1-Y: Rows 44-47 and part of 48. Orchard of variant types used as stocks in orchard 1-Z. Planted in 1922.

1-Z: Rows 48-55. Orchard of Washington Navel orange budded on known types of sour-orange seedlings. Planted in 1922.

$1-Z^{1}$ : On first-grade seedling stocks chosen at seed bed as large.

$1-Z^{2}$ : On second-grade seedling stocks chosen at seed bed as small. 
162 trees. The large, small, and medium trees of each variety were placed in adjacent rows to facilitate visual comparison (see planting plan, fig. 2, orchard $1-\mathrm{X}$, rows 18,19 , and 20). The average size of the trees in each of the large, medium and small groups of each variety at the time of planting, as indicated by area of trunk cross section, is shown in column 2 of table 1 .

The trees were planted 10 feet apart, in rows 24 feet apart, and by 1928 (when they were 11 years old) those in the row planted with large seedlings were crowding each other severely. Every alternate tree was removed in the spring of 1929, to provide for the normal growth of those remaining. Therefore the summary of the results presented here is limited to the period from the spring of 1917 up to the spring of 1928, a total of 11 years. In judging the results it should be borne in mind that during the last 2 or 3 years of this period, the trees (particularly those in the rows planted with large nursery stock) had doubtless been somewhat injured and reduced in size and yield by the crowding.

In this study of the effect of size of budlings (nursery trees) on the later size and yield of the same trees in the orchard, the data used are derived from measurements of trunk area, top volume, and total yields of each tree during 6 years. The average yields were derived from the weight of fruit, in pounds, produced annually during the last 6 years of the period (crops of 1922-23 to 1927-28 inclusive), thus beginning after the trees had reached bearing age (first measurement made in sixth year). The averages of these measurements for each plot are presented in table 1.

TABLE 1

Summary of Results Obtained with Large, Medium, and Small Nursery

Trees as Shown by Averages

\begin{tabular}{|c|c|c|c|c|c|}
\hline \multirow[t]{2}{*}{ Variety } & Tree size & $\begin{array}{c}\text { Average } \\
\text { trunk area } \\
\text { in } 1917\end{array}$ & $\begin{array}{c}\text { Average } \\
\text { trunk area } \\
\text { in } 1928\end{array}$ & $\begin{array}{l}\text { A verage } \\
\text { top volume } \\
\text { in } 1928\end{array}$ & $\begin{array}{l}\text { Average total } \\
\text { yield per tree, } \\
\text { 6-year period }\end{array}$ \\
\hline & 1 & 2 & 3 & 4 & 5 \\
\hline $\begin{array}{l}\text { Washington Navel } \\
\text { orange }\end{array}$ & 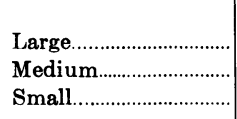 & $\begin{array}{r}\text { sq. cm. } \\
5.052 \\
2.241 \\
1.355\end{array}$ & $\begin{array}{r}\text { sq. cm. } \\
119.43 \\
110.44 \\
95.97\end{array}$ & $\begin{array}{l}\text { cu. ft. } \\
620.61 \\
508.27 \\
440.29\end{array}$ & $\begin{array}{r}l b s . \\
419.5 \\
416.0 \\
350.3\end{array}$ \\
\hline Valencia orange & 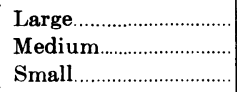 & $\begin{array}{l}5.275 \\
2.055 \\
1.057\end{array}$ & $\begin{array}{l}161.40 \\
138.15 \\
140.60\end{array}$ & $\begin{array}{l}858.00 \\
664.83 \\
712.93\end{array}$ & $\begin{array}{l}349.17 \\
320.78 \\
425.69\end{array}$ \\
\hline Marsh grapefruit & 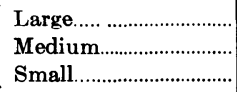 & $\begin{array}{l}7.404 \\
2.750 \\
0.871\end{array}$ & $\begin{array}{l}154.43 \\
134.94 \\
120.20\end{array}$ & $\begin{array}{l}710.93 \\
557.44 \\
434.33\end{array}$ & $\begin{array}{l}783.64 \\
693.97 \\
576.73\end{array}$ \\
\hline
\end{tabular}


It will be seen from an examination of the data given in table 1 that, during the 11-year period up to 1928 in which the trees were growing in the grove, in general the large trees remained large; the medium trees, medium; and the small trees, small (fig. 3) ; and also that the size of the yield corresponds to the size of the tree. The one exception among the 9 plots is found in the Valencias, where the 18 small trees are larger in size than the medium trees and have given a better average yield than either the medium or large trees.

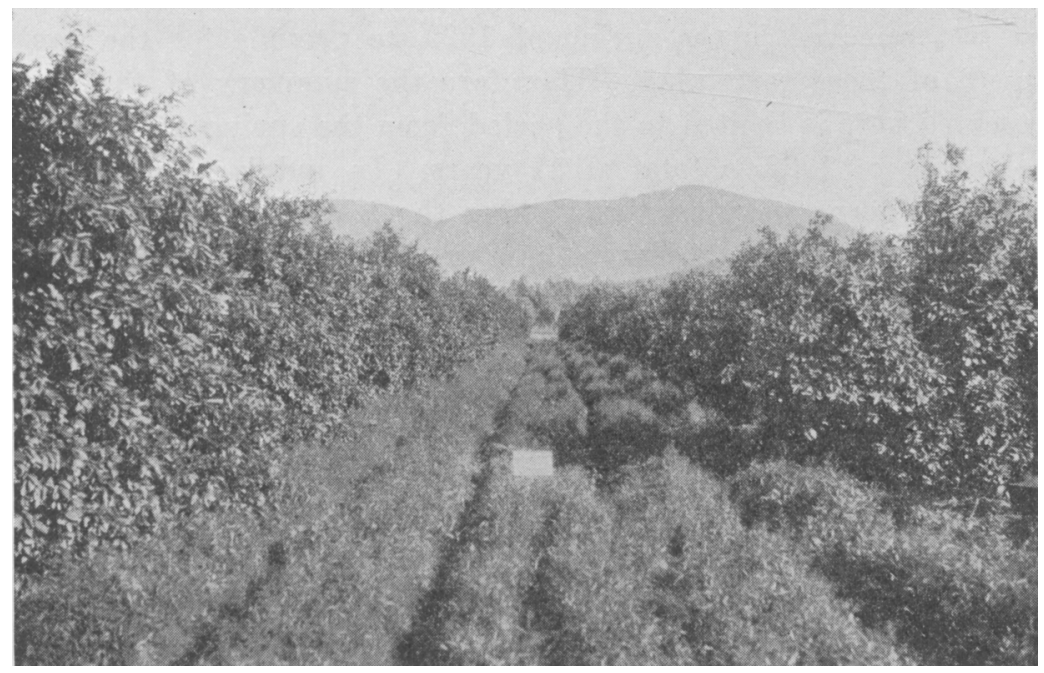

Fig. 3. Marsh grapefruit trees, 13 years old, on sweet-orange stocks showing the influence of budling selection on tree size. Row on left grown from selected large budlings; row on right grown from small budlings. Photographed January, 1930 .

In order to obtain a more exact expression of the size and yield relations of these trees, the whole population (large, medium, and small) of each variety was considered together. The coefficients of correlation were determined for trunk area of original nursery tree in 1917 with 1928 trunk area, with 1928 top volume, and with average 6 -year yields. These data are given in table 2 .

It will be seen from an examination of these data for the combined populations that significant correlations exist in all cases where size is considered. If area of trunk cross section of the budlings is compared with similar measurements of the corresponding 11-year-old orchard trees, the coefficient for the Washington Navel is $+0.394 \pm 0.082$; for the Valencia, $+0.362 \pm 0.082$; and for the Marsh, +0.460 
\pm 0.077 . These correlations are moderately large and in each case they are more than four times larger than their respective probable errors and may thus be considered significant.

The same is true for all varieties when area of trunk cross section of budlings is compared with top volume of orchard trees, the correlations being for Washington Navel, $+0.452 \pm 0.072$; for Valencia, $+0.390 \pm 0.081$; and for Marsh, $+0.582 \pm 0.064$. These are slightly larger correlations than those obtained when trunk area of budling was compared with trunk area of orchard trees, and it will be noticed that in each case they are about the same relative amount larger.

TABLE 2

Correlation of Size of Budlings with Size and Yield of Orchard Trees (All on SWEET-Orange Stocks)

\begin{tabular}{|c|c|c|c|}
\hline Variety & $\begin{array}{l}\text { Number in } \\
\text { population }\end{array}$ & Data correlated & $\begin{array}{c}\text { Coefficient of } \\
\text { correlation }\end{array}$ \\
\hline $\begin{array}{l}\text { Washington Navel } \\
\text { orange }\end{array}$ & $\begin{array}{l}49 \\
49 \\
49\end{array}$ & 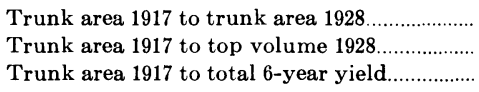 & $\begin{array}{l}+0.394 \pm 0.082 \\
+0.452 \pm 0.072 \\
+0.170 \pm 0.092\end{array}$ \\
\hline Valencia orange & $\begin{array}{l}52 \\
52 \\
52\end{array}$ & 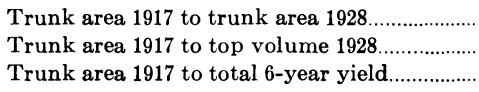 & $\begin{array}{l}+0.362 \pm 0.082 \\
+0.390 \pm 0.081 \\
-0.141 \pm 0.093\end{array}$ \\
\hline Marsh grapefruit & $\left\{\begin{array}{l}47 \\
47 \\
47\end{array}\right.$ & 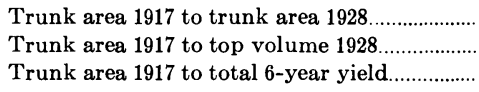 & $\begin{array}{l}+0.460 \pm 0.077 \\
+0.582 \pm 0.064 \\
+0.410 \pm 0.085\end{array}$ \\
\hline
\end{tabular}

The difficulty of obtaining trustworthy comparative results from plot experiments, unless the plots are replicated several times, is well recognized. It is, nevertheless, considered particularly significant that the trees in each of these 9 plots should have continued for a period of 11 years to exhibit approximately the same relative size that they did in the beginning of the experiment.

Trunk measurements of these trees were taken several times during the 11-year period of the experiment, and it is of interest to note that the average size of each group has continued throughout in about the same relative position. This is shown graphically for the Washington Navels and Valencias in figure 4. The average size of the trees remaining in 1931 after the thinning of the orchard is included in this graph.

It will be seen from an examination of the graph that the lines representing the relative increase in size of the trees of each group rise rapidly and gradually approach nearer together as the trees grow 
older. The large group of trees in each case still retains its superiority, but it is indicated that in a longer-continued period of time the relative increase of the large and small trees in each varietal group may become equal.

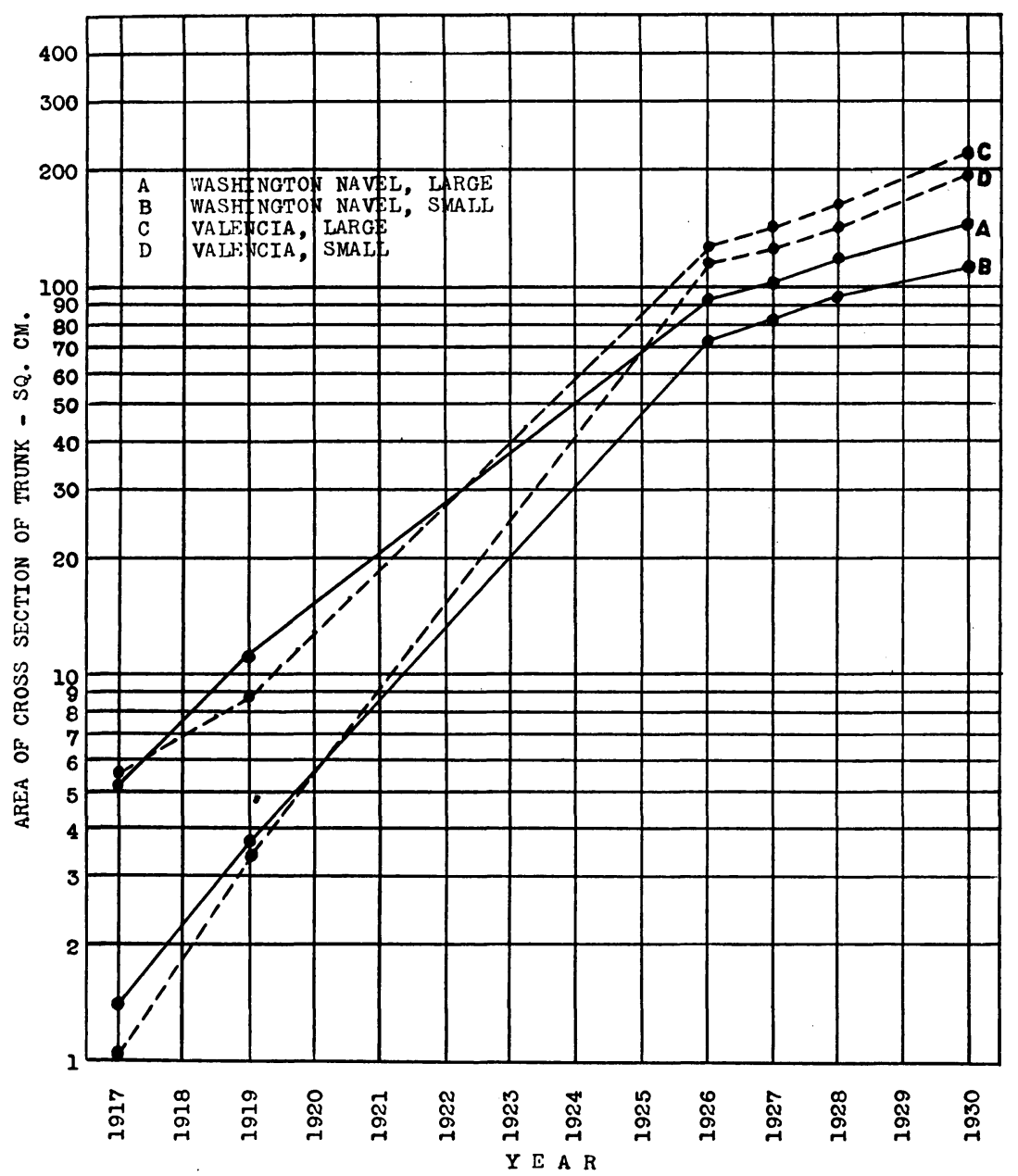

Fig. 4. The relation of relative increase in size at various intervals of time, for the large and small trees of Washington Navel and Valencia oranges as shown by area of trunk cross section. Solid lines, Washington Navel: $A$, large; $B$, small. Dash lines, Valencia: $C$, large; $D$, small.

In the case of the yields, the results from these plots show some complications. In Marsh grapefruit, the correlation of 1917 budling trunk area with average total 6 -year yield, which is $+0.410 \pm 0.085$, 
would be considered as significant. However, the same correlation with the Washington Navel is only $+0.170 \pm 0.092$, which is not twice as large as the probable error and could scarcely be considered as significant, and with Valencia is $-0.141 \pm 0.093$, a negative correlation which would certainly not be considered significant.

It is unfortunate that in this experiment the plots of differentsized trees were not replicated several times with each variety to furnish a direct check on any outstanding difference, such as is shown by this one plot of small budlings of Valencia. The other 8 plots may be considered in a sense as check plots since they have all retained their same relative rank in all of the three characters measured.

In the studies of Parker and Batchelor (1932) on the early yields during the first 10 years of the different plots of Washington Navels that were to be used in the fertilizer experiments of this Station, it was found that adjacent plots frequently varied greatly in yield and maintained the same rank uniformly throughout the first 10 years (6 fruiting years) during which time all plots were treated uniformly. Such differences were assumed to be due to soil variations or possibly to some extent to differences in methods of planting used by different planting crews, although all trees were handled as nearly alike as possible. These fertilizer experiments are on the same type of soil in the same field as the writer's experiments and thus it appears probable that certain limited patches of soil which seem to be uniform vary sufficiently to be responsible for these variations in plot yields.

While it seems probable that soil variation may be responsible for the exceptional result produced by the Valencia plot of small trees, no outstanding difference in the soil can be observed. Furthermore, the trees in this experiment so far as can be traced in the records or from the memory of those who did the work, were all planted by the same crew. The reason why this one plot of Valencias forms an exception cannot be clearly explained at the present time.

It is probable that during the last 2 or 3 years of the entire 12 years of this experiment, the plots of large budlings were slowed up, in growth and yield, more than those planted with medium or small budlings, due to the crowding, which was most noticeable in the row planted with large budlings. At least it is certain that whatever effect resulted from the crowding would have been favorable to the plots of small trees.

When all factors are considered, however, the fact remains that the evidence from the records of comparative area of trunk, volume 
of top, and even of yield during the period of the experiment, in general indicates the continued superiority of the selected large budlings over the small ones.

If this is the case, which was not assumed when the experiment was started, it is important to determine, if possible, the factor or factors fundamentally responsible for this variation in budlings in order that the largest possible proportion of the superior budlings may be grown, and means found of eliminating the inferior ones.

In the propagation of the trees used in this experiment, buds were taken from carefully selected trees of known performance record, except in the case of the Valencias, the buds for which were taken from good trees true to type, but the performance records of which were not known. It is assumed, however, that the variations in size of budlings were probably not due to differences in the buds used.

When the budlings were dug in order to transplant them into the orchard, they were taken up "bare root" and the roots carefully examined for possible malformations or diseases that might render them inferior. No individuals were chosen for planting except those that were judged to have normal healthy roots, and thus it is not believed that malformation of the roots or any diseased condition can be considered as responsible for the small trees in this experiment.

The bud unions were also carefully examined and all the plants chosen had apparently healed over promptly and formed normal unions.

Probably the most common causes for ordinary variations in size of nursery trees and plants in general are local variations in the environment under which they are grown, such as richness of soil, texture of soil, moisture supply, etc. If, however, such environmental factors in the nursery were responsible for all of the variations in size among the budlings used in this experiment, it would seem probable that when the trees were removed and planted in the orchard under new environmental conditions, in most cases they would soon have responded to the new conditions and grown out of their original rank of size. It would seem that the very slight handicap in size of the small budlings, if caused only by the nursery environment, would soon be overcome and be unrecognizable in the new environment. Some of the small budlings have indeed produced good-sized trees and some of the large budlings have not retained their original rank in size, but in general, the small have remained small and the large have remained large. 
The only other obvious variable is that introduced by the rootstocks, and these were seedlings of good selected sweet-orange trees, but of unknown heritage. They were taken from a bed in which the seedlings had made excellent growth and the smallest seedlings to the extent of about 10 per cent of the total number had been discarded when the seedlings were dug and transplanted to the nursery. Seedlings of many citrus species are known to be more or less variable. Most of the varieties grown are known to be heterozygous for many characters so that they do not reproduce true through the seed. Thus it may seem reasonable to suppose that the seedlings used as stocks at least in many cases, were variable and of hybrid nature for certain characters so that they might be expected to react differently upon the scions grown on them. However, the selection preceding the budding had probably eliminated most of the variants, so that there remained a nearly homogeneous lot of seedlings of apogamic origin.

This experiment served to focus attention on rootstocks as a probable cause of variation in the size of orchard trees. It also pointed out the necessity for a more careful study of variations occurring among seedlings, and the influence of such variations on the size and general character of the trees of varieties worked on them.

\section{REACTION ON SCIONS CAUSED BY DIFFERENT-SIZED ROOTSTOCK SEEDLINGS}

\section{Plan of Experiment}

In order to obtain definite evidence as to the reaction on scions caused by rootstock seedlings of different size and type, it was necessary to make actual trials, and such an experiment was started in $1919 .{ }^{11}$

11 This experiment, which was planned and started by the writer, was carried out during the important period from 1921 to 1926 by Dr. J. T. Barrett, then Acting Director of the Citrus Experiment Station. Dr. Barrett thus deserves much credit for the results obtained, but is not to be held responsible for the interpretation of the results and the conclusions reached as stated in this paper. Figures 6 to 12 are from photographs taken by Dr. Barrett. The writer again took charge of the experiments in 1926.

A preliminary report on this experiment, prepared by the writer in cooperation with Dr. Barrett, was presented before the Ninth International Horticultural Congress held in London, England, August 8 to 15, 1930, and was published in the proceedings of the Congress (Webber and Barrett, 1930). Some of the discussion of this experiment given in the present paper is taken with little clange from that report, but the data are given here in more detail, and considerable new material has been added. 
Sour-orange seedlings were taken from an ordinary seed bed grown at the Citrus Experiment Station in the spring of 1919 when they were 1 year old, and the very smallest seedlings were discarded, to the extent of about 10 per cent of the total population. Such very small seedlings are commonly discarded by nurserymen when a seed bed is dug, because they are too small to transplant well and usually fail to grow after transplanting. The remaining seedlings, ranging in height from about 4 to 12 inches, were then examined and segregated by sight judgment into two lots by size (large and small), and these lots were planted separately in the nursery. These will be designated in the further discussion as first and second grade, or merely as firsts and seconds.

After they had grown one year in the nursery, the lot of firstgrade large seedlings, 301 in number, ranged in height from 5 to 30 inches with an average of 18.19 inches, while the lot of second-grade small seedlings, numbering 228, ranged from 2.5 to 20 inches in height with an average of 9.07 inches (Webber, 1920a, p. 292). A considerable number of the small and weak seedlings, especially among the seconds, had died before measurements were taken.

These seedlings were given permanent individual numbers in the spring of 1921 and were carefully studied as to type and size (diameter and height), after which they were budded with buds taken from one carefully selected Washington Navel tree. ${ }^{12}$ In the spring of 1922 these budded trees were planted in a permanent experimental orchard, in the same order that they occupied in the nursery, and this orchard is here designated as orchard $1-Z$ (see planting plan, fig. 2).

At the time when the tops of the above seedlings were cut off to force the Navel buds into growth according to the common nursery practice, bud sticks were taken from the tops of each variant seedling, and two trees were budded with each, one on Rough-lemon stock, and one on sour-orange stock. By this means, two trees representing the type of each of the variant sour-orange seedlings, which were budded to Washington Navels, were retained as budded trees in order to permit the study of their mature tree characters. Each was propagated on two different rootstocks in order that judgment might be formed

12 The buds used for this purpose were from tree 3-14-27, located on the Vivienda Ranch of the National Orange Company at Highgrove, California, which was the tree ranking No. 1 in the block of performance-record trees studied and described by Shamel, Scott, and Pomeroy (1918). The Station is greatly indebted to the National Orange Company and to A. D. Shamel and his coworkers for the privilege of using buds from this tree. 
as to whether the rootstock influenced in any material degree the type of the variant.

The nursery trees propagated from these variant seedlings were also planted in an experimental orchard adjoining orchard $1-Z$, and is here referred to as orchard 1-Y (see fig. 2).

These two orchards, No. 1-Z and No. 1-Y, were 8 years old in 1.929 when this study of the data was started, and had been fruiting for several years. This experiment furnishes a case where the results from growing uniform buds on known types of seedlings, normal and variant, can be studied and the reactions observed (orchard 1-Z); and if a tree on a seedling that was classed as a variant shows any peculiar reaction in orchard $1-Z$, the type of that particular variant can be studied in the orchard of variant types (orchard 1-Y).

In the propagation of the budlings for this experiment, 289 firstgrade seedlings were budded, and among these 16, or 5.5 per cent, were distinguished as variants. Two hundred and ten second-grade seedlings were budded, among which 69 , or 32.9 per cent, were distinguished as variants. The variants were so classed not only because of their size but also because of morphological differences.

There was some loss from buds that failed to grow and a considerable number of trees have died in the course of the experiment, particularly those on variant seedling roots, so that the population remaining for study and comparison has been reduced to 241 of the large first-grade stock seedlings, among which there are 10 that were classed as variants; and 148 of the small second-grade stock seedlings, among which there are 33 that were classed as variants. The much greater frequency of variant types among the smaller-sized or secondgrade seedlings as separated at the time they were dug from the seed bed, is very noteworthy.

The original size of the rootstock seedlings at the time of budding as shown by the area of cross section of trunk 4 inches above the ground, has been compared with the size of scion trunk when 1 year old in the nursery and when 8 years old as indicated by area of trunk crcss section. Studies and comparisons have also been made between the size of the scion trunk when 1 year old (as a nursery tree) and the size the same trees have attained after 8 years' growth in the orchard as shown by area of trunk cross section, and with the yield as shown by the total yields of each tree up to 1930. Use has been made of the ordinary statistical constants such as the mean, standard deviation, ccefficient of variability, and coefficient of corre- 
lation, in determining the growth relation and yield for the entire population and for various groupings of the population in different cases.

\section{Permanence of Variant Types}

In the consideration of the data derived from this experiment it is desirable first to know whether the variants noted among the population of seedlings used as stocks have continued to show differential characters indicating genetic differences.

Orchard 1-Y, where each of these variants was propagated upon two different rootstocks, presented after 8 years of growth, a medley of types that would be difficult to exceed if one were to bring together all of the most diverse species of Citrus (fig. 5). A very few of those chosen as variants approach closely to the normal type of the sour orange and are of approximately normal size for their age (fig. 15, tree 46-32). Many remain veritable dwarfs, being only $2 \frac{1}{2}$ to 3 feet high (fig. 9) at an age when normal sour-orange trees should have reached 10 feet or higher. All sizes between these two extremes are exhibited by the different variants (figs. 11, 13, and 15). Other characters apparently exhibit fully as great a range of variation as does size, and one finds extremes of coarse and slender branching, open and dense foliage, long and short leaves, broad and narrow leaves, broadly winged and nearly wingless petioles, large and small fruits, light yellow and orange-red fruits, well-developed glands and strong odor or atrophied glands and odorless. Some of the trees with shapely tops of finely branched stems and with dense foliage of slender pointed leaves would scarcely be recognized as citrus trees. The great majority of them exhibit some degree of sterility and some have as yet shown no indication of flower development.

It is important to note that the two different rootstocks, Rough lemon and sour orange, used in the propagation of each of these variants, has had little or no influence on the type of the variant as indicated by the visible characters. The trees of each type on the two stocks are growing side by side and invariably show the same characteristics. The trees on Rough-lemon stock, in general, are somewhat larger than those of the same type on sour stock, though there are some exceptions. Invariably, however, the distinctive character of the type remains unchanged. If it is a dwarf type both trees are relatively dwarfed, or if it is a dense-foliage type with long narrow leaves, both trees show the same characters without reference to the stock. The Rough lemon is a very vigorous-growing stock, 
very distinct from the sour orange, and it is rather surprising that these widely variant types of the sour orange when budded onto it show such slight differences, or stionic effects, in comparison with the same trees budded on a standard type of the sour orange where the affinity is certainly much closer (figs. 5 and 9 ). The only differences observable without an exhaustive study are limited to size characters, indicating that the stock is to be considered here merely as furnishing a different environment for the growth of the scion, which it affects only in such characters as are modified directly by the environment. The results here are entirely confirmatory of those obtained in the experiment outlined in a preceding section.

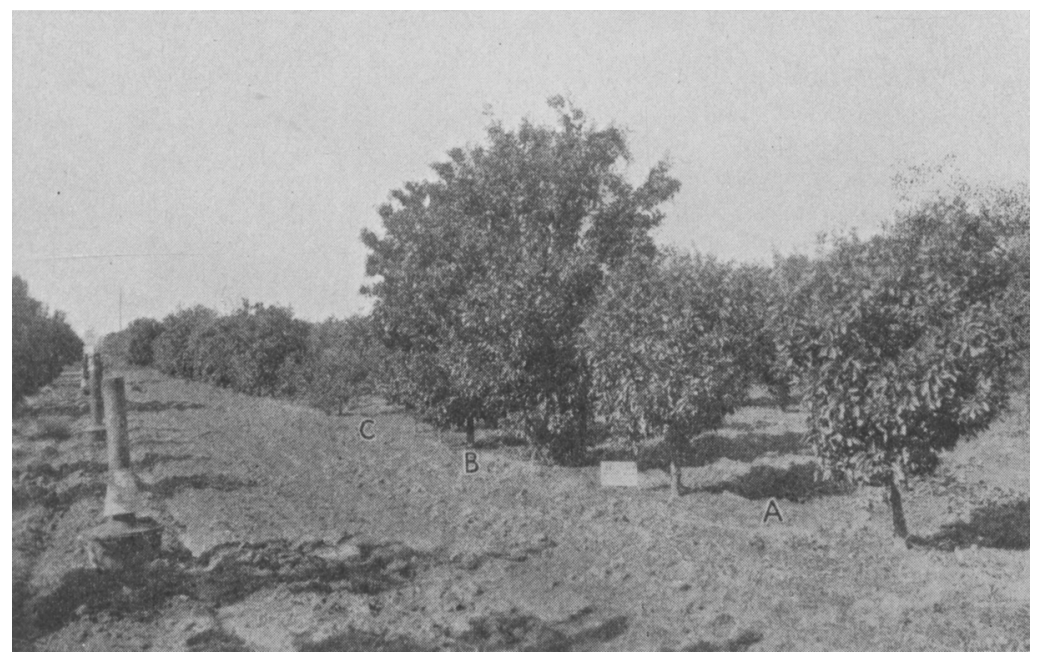

Fig. 5. Variant sour-orange types used as stocks (orchard 1-Y, row 46); two trees of each variant, the one on the right of each couple being propagated on Rough-lemon stock and that on the left on sour-orange stock. Note that the character of each variant remains unchanged by stock influence. The variant seedling from which couple $A$ was propagated is the stock of Washington Navel $49-25$; couple $B$ is the stock of $49-26$; and couple $C$ the stock of $49-27$; see figure 6. All 8 years old.

\section{Influence of Variant Seedlings in Producing Dwarfed Orchard Trees}

Greatest interest centers in orchard $1-Z$ where the variant seedlings represented in orchard $1-Y$ are used as rootstocks, together with the normal seedlings in the same population. As the buds from one single selected Washington Navel tree were used in propagating 
these trees, they should be exceptionally uniform. Such is the case with the lot of large seedlings, but the small seedlings have given a highly variable lot of trees as judged by size (figs. 6 and 7 ). A tabulation of the results shows that almost every seedling that was classed as a variant has, when budded, produced an orchard tree exhibiting some degree of dwarfing and in the majority of cases very marked dwarfing (fig. 8, tree 49-15; fig. 10, tree 50-14; and fig. 14, tree 49-25). This is the case even where the variant itself is nearly

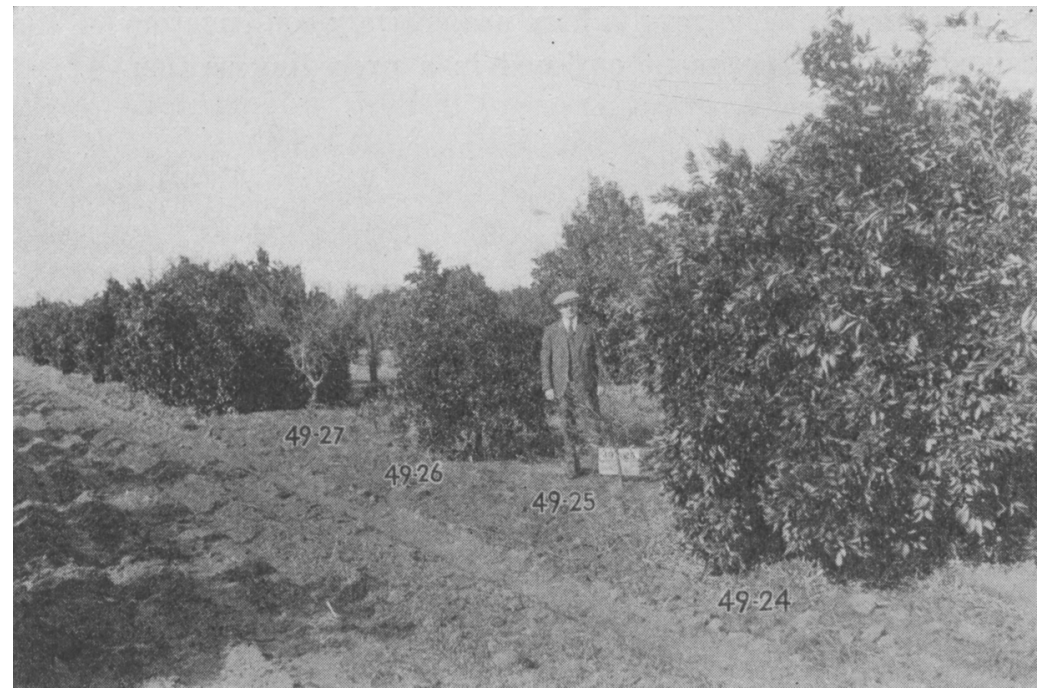

Fig. 6. Washington Navel orange on sour-orange stocks: tree 49-24 on normal stock; tree 49-25 on variant seedling stock (see fig. 5A) ; tree 49-26 on variant seedling stock (see fig. $5 B$ ); tree $49-27$ on variant seedling stock (see fig. $5 C$ ). Note the variation in size due to stock. All 8 years old, orchard 1-Z", row 49 .

normal in size, indicating only a slight depression of the normal growth rate as shown by its growth in orchard 1-Y (compare figs. 10 and 11$)$.

As the largest proportion of the variant types was in the lot of small seedlings, the portion of orchard $1-Z$ planted with second-grade small stock seedlings $\left(1-Z^{2}\right)$ shows a higher proportion of these dwarfed trees, while the portion of orchard $1-Z$ planted with large stock seedlings $\left(1-Z^{1}\right)$ shows only a very small number of such trees. For an understanding of this section compare figures 6 to 15 inclusive. 


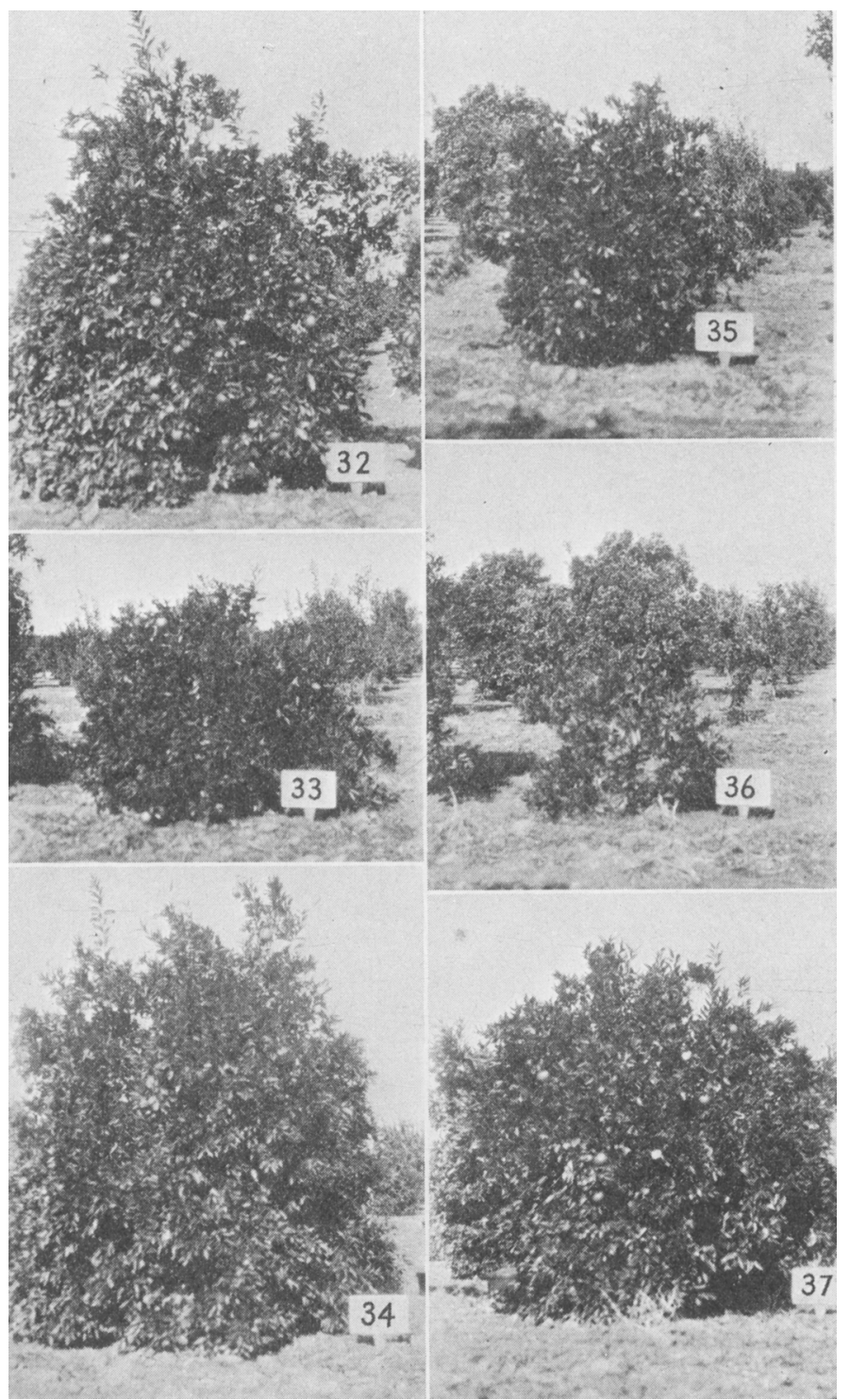

Fig. 7. Six consecutive trees in row 49 of Washington Navels on second-grade seedlings of sour orange in orehard $1-\mathrm{Z}^{2}$. Trees 32,34 , and 37 are normal-sized trees on seedlings of normal type. Trees 33,35 , and 36 are dwarfed trees on seedlings of variant type. All trees 8 years old. Note the different degrees of dwarfing. 


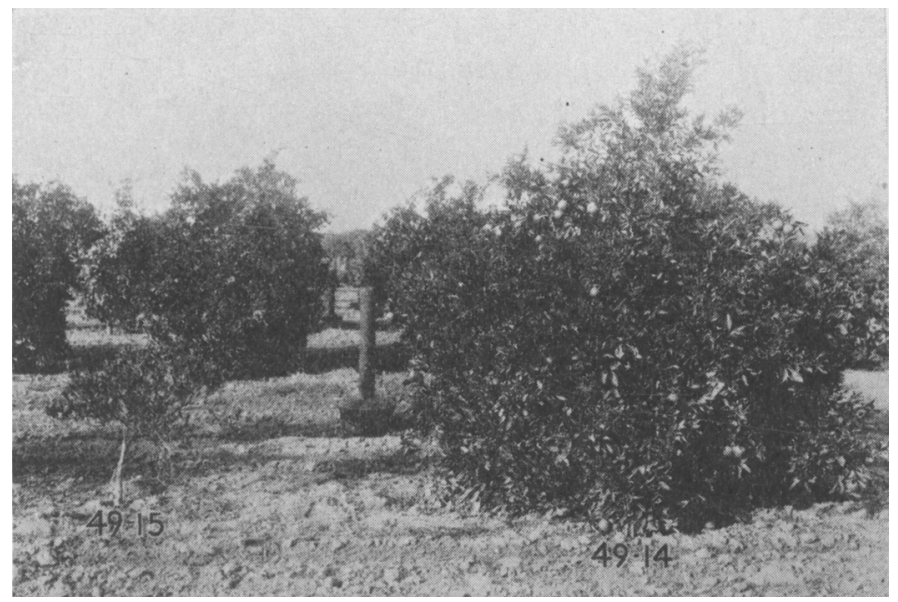

Fig. 8. Washington Navel orange on sour-orange stocks: tree 49-15, a dwarfed tree on a variant seedling stock (see fig. 9, trees 46-12 and 46-13) ; ${ }^{*}$ tree 49-14, a normal-sized tree on a normal sour-orange seedling. Trees 7 years old.

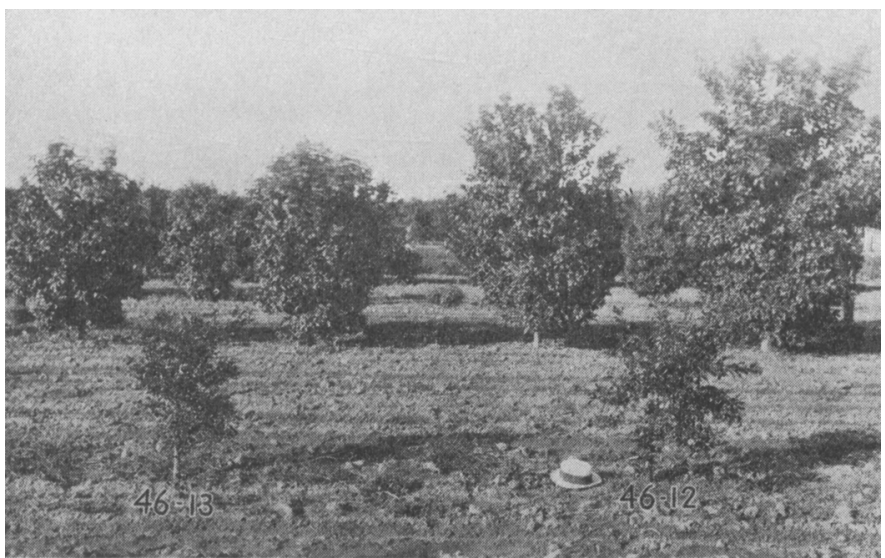

Fig. 9. Variant sour-orange types used elsewhere as stocks: trees 46-12 and 46-13 were propagated from a small dwarf seedling which is the stock of Washington Navel 49-15 in figure 8. Note also the variation in the other variant sour-orange types in the background. The couple immediately in rear of tree 46-12 propagated from one variant seedling, show clearly that they are the same type, although the one on the right, which is on Rough-lemon stock, is slightly larger than the other, which is on a normal sour-orange stock. The couple immediately in rear of tree 46-13 are propagated from still another variant seedling and are intermediate in size between the other two types shown in this photograph. Trees 7 years old. 


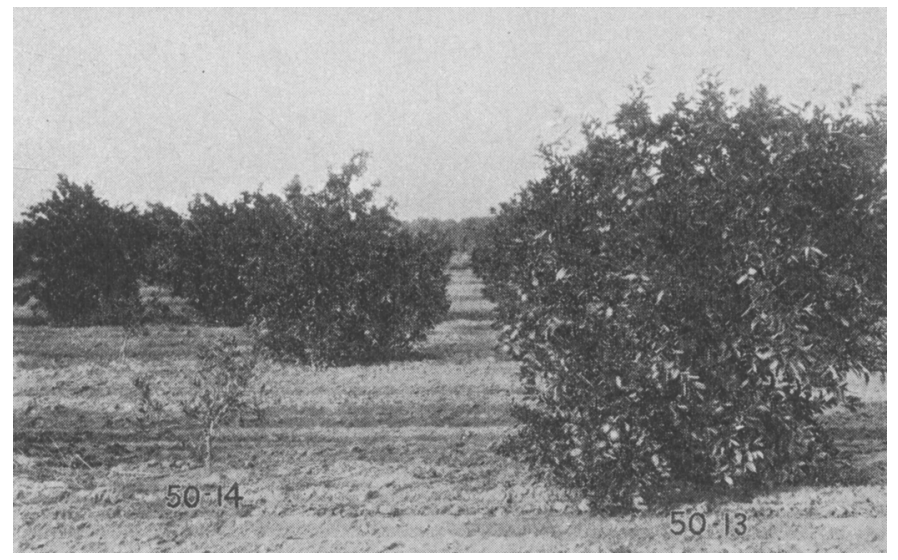

Fig. 10. Washington Navel on sour-orange stocks: tree 50-14, a dwarf tree on a variant seedling stock (see fig. 11, trees 47-23 and 47-24); tree 50-13, a standard-sized tree on a normal sour-orange seedling. Trees 7 years old.

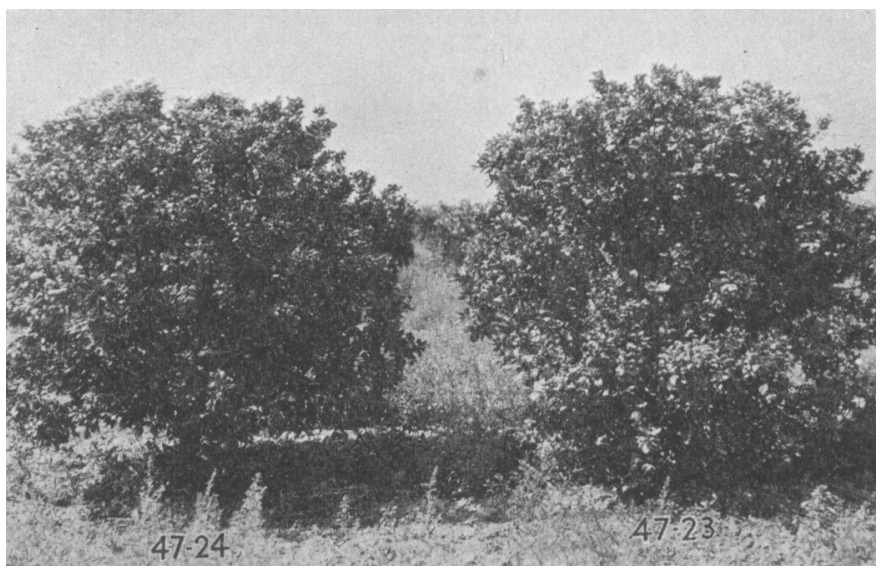

Fig. 11. Variant sour-orange types used elsewhere as stocks: tree 47-23 on Rough-lemon stock and 47-24 on sour-orange stock, both propagated from the same variant seedling used as the stock of Washington Navel 50-14 in figure 10. This is an instance of a nearly normal-sized variant which as a stock dwarfs the scion. Trees 7 years old. 


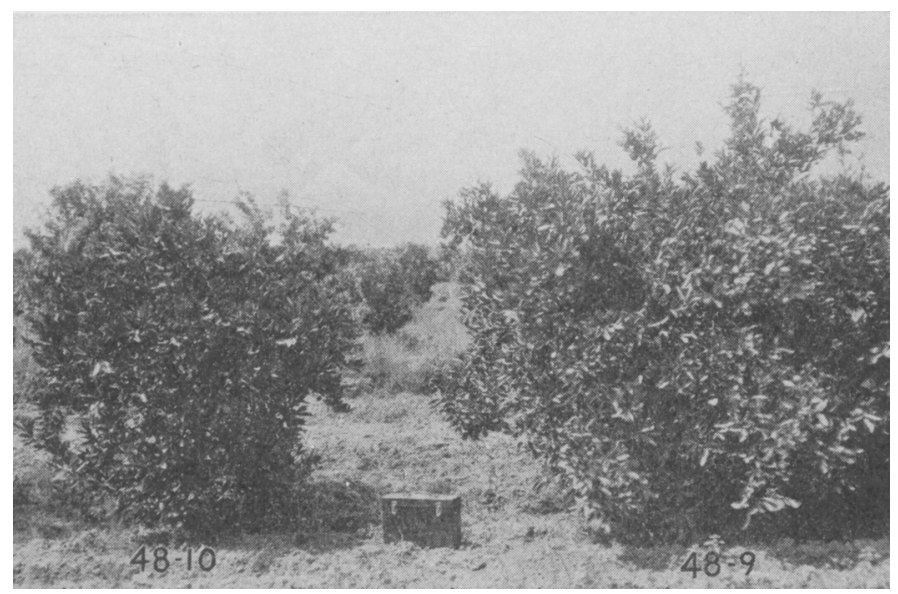

Fig. 12. Washington Navel on sour-orange stocks: tree 48-10, a slightly dwarfed tree on a variant seedling stock (see fig. 13, trees 45-13 and 45-14); tree 48-9, a standard-sized tree on a normal sour-orange seedling. This is a case of a vigorous-growing variant that produces only a slight dwarfing effect. Trees 7 years old.

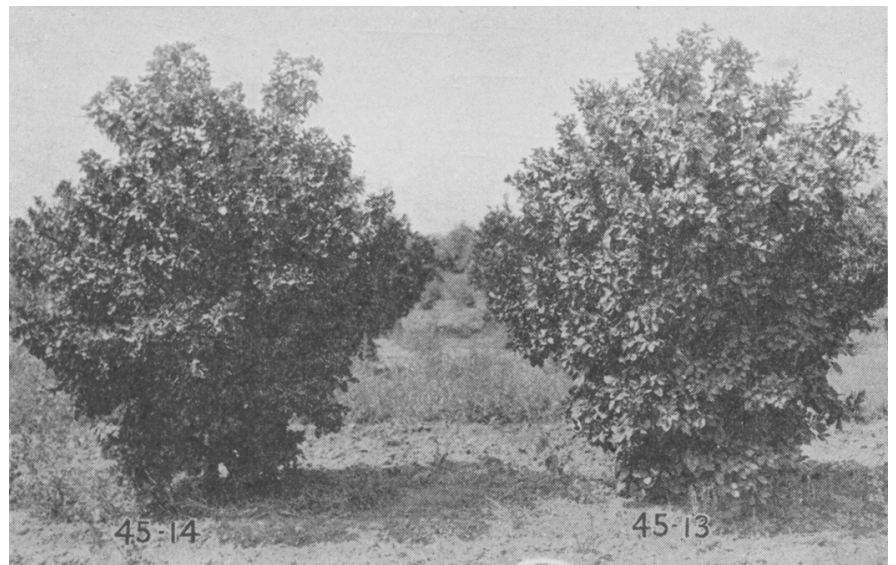

Fig. 13. Variant sour-orange types used elsewhere as stocks: tree 45-13 on Rough-lemon stock and tree 45-14 on normal sour-orange stock, both propagated from the same variant seedling used as the stock of Washington Navel tree 48-10 in figure 12. Note the same general type of these two trees although on widely different stocks. Trees 7 years old. 


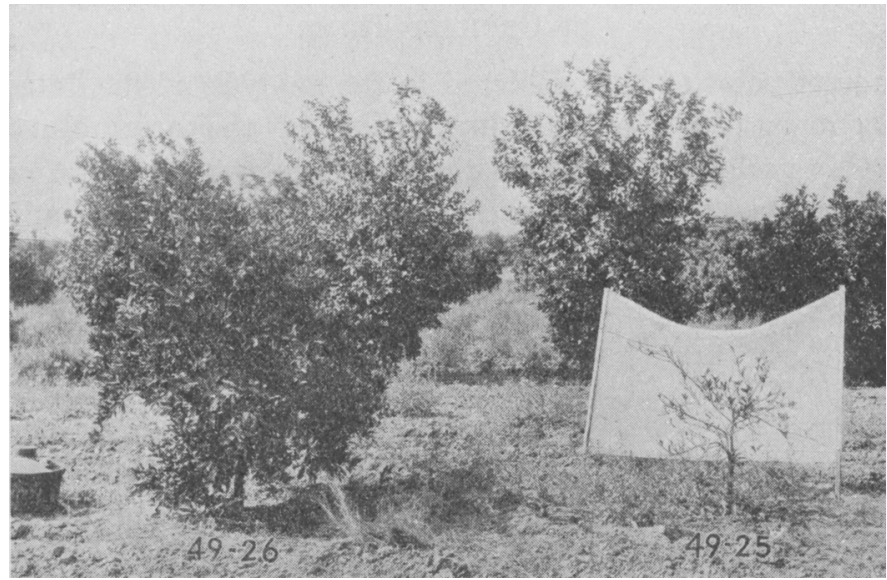

Fig. 14. Washington Navel on sour-orange stocks: tree 49-25, a severely dwarfed tree on a variant seedling stock (see fig. 15, tree 46-30); tree 49-26, a slightly dwarfed tree on a large vigorous-growing variant stock (see fig. 15, tree 46-32). Trees 7 years old.
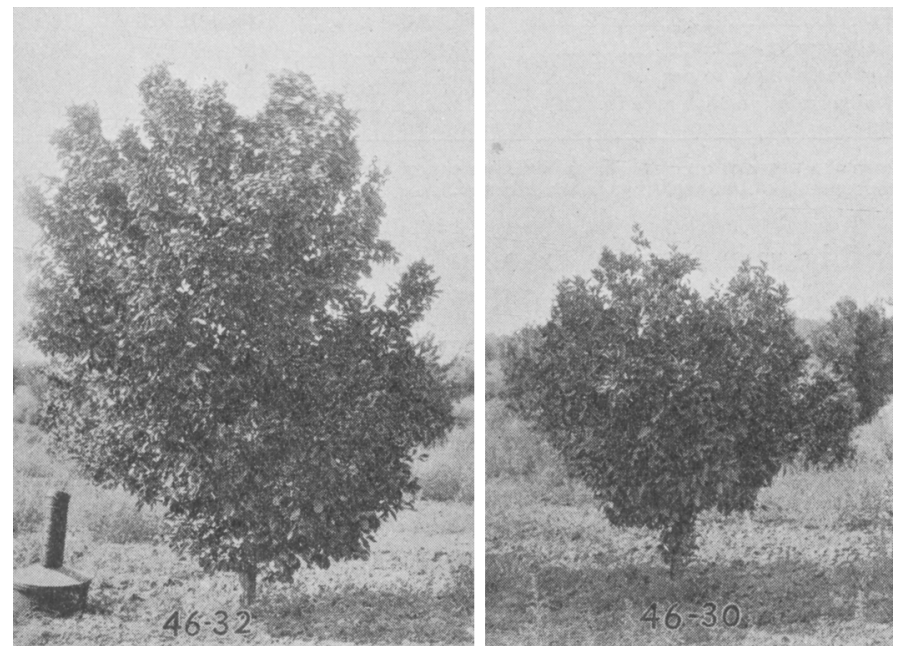

Fig. 15. Variant sour-orange types used elsewhere as stocks: tree 46-30, on Rough-lemon stock, a medium-sized variant propagated from seedling used as stock of tree 49-25 in figure 14; tree 46-32, on Rough-lemon stock, $\boldsymbol{a}$ large variant propagated from seedling used as stock of tree 49-26, in figure 14 . Trees 7 years old. 


\section{Influence of Size of Rootstock Seedlings on Size and Yield of Orchard Trees}

The next point to be considered in the analysis of the data on this experiment is the effect which the size of the original rootstock seedlings in orchard $1-Z$ had on the size of the scions grown on them. In table 3 the statistical constants for this entire population of trees are given at three periods, namely, for the size of the rootstock seedlings in 1921, size of scion in 1922, and size of scion in 1929, with correlations between the two latter and the former.

\section{TABLE 3}

Comparison of Size of Rootstock Seedlings at Time of Bunding with Size of Budlings at 1 Year and 8 Years

(Area of cross section of seedling trunk in 1921 with area of cross section of scion trunk in 1922 and 1929 , respectively ; population $397^{*}$ )

\begin{tabular}{|c|c|c|c|}
\hline \multirow[b]{2}{*}{ Constants } & \multicolumn{3}{|c|}{ Area of trunk } \\
\hline & $\begin{array}{c}\text { Stock seedlings, } \\
1921 \\
\text { (4 in. above soil) }\end{array}$ & $\begin{array}{l}\text { Scion, } 1922 \\
\text { (2 in. above } \\
\text { bud union) }\end{array}$ & $\begin{array}{l}\text { Scion, } 1929 \\
(6 \text { in. above } \\
\text { bud union) }\end{array}$ \\
\hline Age of population.. & 3 yrs. from seed & 1-yr. budlings & 8-yr. trees \\
\hline Mean, in sq. cm....... & $3.55 \pm 0.053$ & $2.46 \pm 0.032$ & $76.08 \pm 0.671$ \\
\hline Standard deviation in $8 q . \mathrm{cm}$ & $1.53 \pm 0.037$ & $0.93 \pm 0.022$ & $19.55 \pm 0.473$ \\
\hline Coefficient of variability, in per cent.......... & $43.23 \pm 1.228$ & $37.72 \pm 1.035$ & $25.70 \pm 0.662$ \\
\hline Coefficient of correlation with area in 1921 & 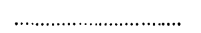 & $+0.736 \pm 0.016$ & $+0.437 \pm 0.028$ \\
\hline
\end{tabular}

* The use of a population of 387 trees here, instead of 389 as in certain other tables, is due to the loss of the measurements of two seedlings in the nursery.

It will be seen from an examination of the data presented in table 3 that the coefficient of variability in size of the 1-year-old budlings is 37.72 per cent, slightly less than that exhibited by the stock seedlings, which is 43.23 per cent. The variability of the trees at 8 years of age is still less, being only 25.70 per cent. In view of the fact that the budlings were all propagated with buds from one selected tree, and therefore presumably all have about the same inherent growth rate, it is rather to be expected that they would show less variation than the variable stock seedlings. Again in the young life of the budlings, variation in the time that the bud starts, owing to minor incidents of variation in method, is likely to show pretty clearly in the size of the top. This variation in budling size is usually more clearly marked during the first year and gradually becomes less evident in succeeding years. 
The very marked relation of the size of the stock seedlings in 1921 at the time of budding, to the size of the 1-year-old budlings propagated on them, while still in the nursery under the same environmental conditions, is clearly shown by the high coefficient of correlation, $+0.736 \pm 0.016$. As the trees become older, after transplanting to the orchard, this degree of correlation is lessened and the scion trunk size of the 8-year-old orchard trees compared with stock trunk size at the time of budding gives a correlation coefficient of only $+0.437 \pm 0.028$. This, however, is a sufficiently large and significant correlation to indicate the general tendency of the large seedlings to produce large trees.

The population of 387 trees in table 3 includes 41 trees which are known to be variants and to produce dwarfed orchard trees. These variants must greatly influence the correlations exhibited when the total population is considered, and it is important to know what occurs when the known variants are excluded from the population and only trees used that are supposed to be of normal type.

In table 4 corresponding data are given for the population exclusive of variants.

\section{TABLE 4}

Relation of Size of Stock Seedlings to Size of Budlings and Orchard Trees, When Variants Are Excluded

(Area of cross section of seedling trunk compared with areas of cross section of scion trunk at different ages; population of 346 )

\begin{tabular}{|c|c|c|c|c|c|}
\hline \multirow[b]{2}{*}{ Constants } & \multicolumn{5}{|c|}{ Area of trunk } \\
\hline & $\begin{array}{c}\text { Stock seedlings, } \\
1921 \\
\text { (4 in. above soil) }\end{array}$ & $\begin{array}{l}\text { Scion, } 1922 \\
(2 \text { in. above } \\
\text { bud union) }\end{array}$ & $\begin{array}{l}\text { Scion, } 1924 \\
(4 \text { in. above } \\
\text { bud union) }\end{array}$ & $\begin{array}{l}\text { Scion, } 1927 \\
\text { (4 in. above } \\
\text { bud union) }\end{array}$ & $\begin{array}{l}\text { Scion, } 1929 \\
(6 \text { in. above } \\
\text { bud union) }\end{array}$ \\
\hline Age of population.. & $\begin{array}{l}3 \text { years from } \\
\text { seed }\end{array}$ & $\begin{array}{l}\text { 1-year-old } \\
\text { budlings }\end{array}$ & $\begin{array}{l}\text { 2-year orchard } \\
\text { trees }\end{array}$ & $\begin{array}{l}\text { 6-year orchard } \\
\text { trees }\end{array}$ & $\begin{array}{l}\text { 8-year orchard } \\
\text { trees }\end{array}$ \\
\hline $\begin{array}{l}\text { Mean in sq. cm } \\
\text { Standard deviation }\end{array}$ & $3.87 \pm 0.046$ & $2.69 \pm 0.025$ & $9.73 \pm 0.065$ & $53.54 \pm 0.309$ & $81.05 \pm 0.422$ \\
\hline in sq. $\mathrm{cm}$ & $1.28 \pm 0.033$ & $0.68 \pm 0.018$ & $1.79 \pm 0.046$ & $8.52 \pm 0.218$ & $11.63 \pm 0.298$ \\
\hline $\begin{array}{l}\text { Coefficient of varia- } \\
\text { bility, in per cent }\end{array}$ & $33.05 \pm 0.934$ & $25.43 \pm 0.692$ & $18.43 \pm 0.488$ & $15.92 \pm 0.418$ & $14.35 \pm 0.375$ \\
\hline $\begin{array}{l}\text { Coefficient of corre- } \\
\text { lation with } 1921 \\
\text { seedling area......... }\end{array}$ & 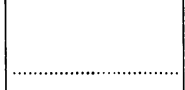 & $+0.549 \pm 0.026$ & $+0.125 \pm 0.036$ & $+0.010 \pm 0.036$ & $-0.021 \pm 0.037$ \\
\hline
\end{tabular}

A number of very significant facts are brought out by the data presented in this table. The coefficient of variability, which, for the seedlings at 3 years of age, just before they were budded, was 33.05 \pm 0.934 per cent, is, for the scions grown on them at 1 year of age, only $25.43 \pm 0.692$ per cent, and this becomes less each year until 
at 8 years of age the variability exhibited is only $14.35 \pm 0.375$ per cent. This shows clearly the general tendency of the degree of difference in size to be smoothed out as the trees grow older.

In this population, where the known variants are excluded, the correlation in size between the seedlings and the 1-year-old budlings as shown by trunk area was only $+0.549 \pm 0.026$, whereas for the entire population with variants included, the coefficient was +0.736 \pm 0.016 . It is thus seen that the variants had a marked influence in increasing the degree of correlation.

The most interesting factor brought out by the data in table 4 is the decreasing correlation between size of trunk area of the seedlings with trunk area of the scions as the trees increase in age. This correlation, which in 1922, when the budlings were 1 year old, was +0.549 \pm 0.026 , had fallen in 1924 to $+0.125 \pm 0.036$, in 1927 to +0.010 \pm 0.036 , and in 1929 when the orchard trees were 8 years old to $-0.021 \pm 0.037$. The last two of these correlations, one slightly positive and the other slightly negative, seem to indicate clearly that the correlation which existed between the size of the seedlings and the size of the 1-year-old budlings entirely disappears as the trees grow older, and that there is no permanent and sustained relation through the life cycle of those trees of the population that remain after the variants are excluded. This is very significant, if it represents the general conditions in other similar citrus populations.

The above data concern only the size of the stock seedlings with relation to the size of the scions grown upon them. It is of some interest to note that the sizes of the trunks of the stocks in the orchard trees react in almost the same way and degree. The trunk area of the stock seedlings correlated with the trunk area of the stocks of the orchard trees when 8 years of age, for the above population of 387 trees including the variants, was +0.398 \pm 0.029 ; while for the same population exclusive of variants, 346 trees gave a correlation coefficient of $-0.054 \pm 0.032$, thus corresponding very closely with the relation shown above in comparing size of seedling with size of scion trunk.

Using the volume of top as a measure of size of the trees in June, 1930, when $81 / 2$ years old, and correlating this with the size of the seedlings as shown by area of trunk, the entire population, exclusive of variants, gave a coefficient of $-0.012 \pm 0.036$. This indicates that there is no significant relation.

It is important also to know the relation between the size of the stock seedlings and the yield of the orchard trees grown on them. 
Here with the entire population exclusive of variants (346 trees), when area of trunk of stock seedlings is compared with the total 5 -year yields of the 8-year-old orchard trees grown on them, there is a correlation of $+0.135 \pm 0.035$. Thus there is in this case a low positive correlation.

These results all indicate that in the population remaining after the elimination of the variants, the original seedling size apparently had but little or no influence on the final orchard tree size and yield.

In an earlier section of this paper attention was directed to the very common occurrence of apogamy in citrus reproduction. In the sour-orange seedlings used as stocks in this experiment it is likely that those classed as variants can fairly safely be considered as coming from sexually produced embryos, while those considered of normal type probably come mainly from apogamic embryos. The individuals remaining in the population after the exclusion of the variants, therefore, are to be considered as of apogamic origin and of the same genetic constitution as the mother parent or parents.

In this limited population with the variants excluded, there is still the possibility of some genetic variation even though all are of apogamic origin. No record was made of the particular tree or trees from which the seed was taken, but since the seed was gathered in the orchards of the Citrus Experiment Station at a period when the plantings were very limited in extent, it is probable that it came from but two or three trees at most and it is possible and even probable that it all came from one single tree. There does not seem to have been suffcient genetic variation in the population with variants removed to insure any permanent influence on the scions as indicated by size characters, and it seems reasonable to conclude, therefore, that this population is probably to be considered as nearly homogeneous genetically.

The seedlings of this population when measured just before the buds were inserted, exhibited a range of variation in area of cross section of trunk of 25.43 per cent. Apparently this variation is mainly environmental.

Soil variability in the experimental orchard (orchard 1-Z) might be expected to influence the variability in both size and yield, and the plotting of the orchard by tree yield shows that certain areas are evidently better than others, but apparently these differences in soil fertility cannot be interpreted as responsible for the final results obtained. 
The seedlings used as stocks in this experiment were in general somewhat larger when budded than is usual in ordinary nursery practice, and it was suggested that the largest ones were probably too large to heal favorably and react equally well on the buds. A large seedling, when budded, does not give a stimulus to growth proportional to its size, as might be expected, since the growth of the bud for a considerable period draws mainly on one side only of the stock. A bud inserted in a stock 1 inch in diameter may not fully grow over the cut trunk of the stock for two years or more, and meanwhile the scion is drawing its supply of soil solutes mainly from a limited part only of the seedling root system, and is very imperfectly supplying the carbohydrate requirements of the large root system.

It is also important to remember that the shock caused by cutting off the top in forcing the buds is likely to be comparatively more severe with the large seedlings than with the smaller ones, and a much longer time may be required to reestablish the normal balanced relation between root and budling shoot than would occur when a smaller seedling is budded. Under such conditions it might be assumed that the large seedling, even if inherently better than a smaller one, would not fully show the influence of its size during a period of possibly several years after budding. The inquiry thus arose as to whether the lack of correlation between seedling size and size of 8-year orchard trees might not be due partially to this influence. If this were true it would seem that the effect might be detected by dividing the seedling population according to size into quartiles, and studying the relations: the small and medium-sized seedlings might be expected to give better results than the very large ones.

Table 5 gives the constants after the division of the population. exclusive of variants, into quartiles based on the trunk area of the seedlings in 1921.

TABLE 5

Relation of Individuals within Quartiles Based on Seedling Size, with VARIANTS EXCLUDED

\begin{tabular}{|c|c|c|c|c|}
\hline Constants & First quartile & Second quartile & Third quartile & Fourth quartile \\
\hline Population in each quartile & 86 & 87 & 87 & 86 \\
\hline $\begin{array}{l}\text { Mean trunk area of seedlings, } 1921 \text {, } \\
\text { in sq. cm }\end{array}$ & $2.47 \pm 0.030$ & $3.31 \pm 0.008$ & $4.19 \pm 0.030$ & $5.54 \pm 0.065$ \\
\hline $\begin{array}{l}\text { Mean trunk area of orchard trees, } \\
1929 \text {, in sq. cm }\end{array}$ & $78.83 \pm 0.969$ & $80.83 \pm 0.654$ & $83.82 \pm 0.866$ & $80.69 \pm 0.821$ \\
\hline $\begin{array}{l}\text { Coefficient of variability, orchard } \\
\text { trees, } 1929 \text {, in per cent............................ }\end{array}$ & $16.92 \pm 0.894$ & $11.19 \pm 0.579$ & $14.29 \pm 0.745$ & $13.99 \pm 0.733$ \\
\hline $\begin{array}{c}\text { Coefficient of correlation, area } 1921 \\
\text { seedlings with } 1929 \text { trees }\end{array}$ & $-0.058 \pm 0.073$ & $+0.0012 \pm 0.075$ & $-0.230 \pm 0.070$ & $-0.251 \pm 0.069$ \\
\hline
\end{tabular}


The examination of the mean size of the orchard trees in each quartile shows that the small and large trees in 1929 are very nearly equally distributed in the different quartiles and that the percentage of variability also is practically the same in each. The correlations in the first and second quartiles are in both instances so small as to indicate no correlation, but those in the third and fourth quartiles, -0.230 \pm 0.070 and $-0.251 \pm 0.069$, are possibly sufficiently large in relation to their probable errors to indicate a tendency for the large seedlings in the third and fourth quartiles to produce somewhat smaller 8-yearold orchard trees. Therefore this may indicate a slight holdover influence of a detrimental effect from budding too large seedlings. The writer is not inclined to consider these figures as more than a suggestion in connection with future work.

It must be granted that the evidence presented here indicates that there is no apparent consistent relation between the size of the stock seedlings after the variants are eliminated and the size of the orchard trees in later years after they have reached an age of 8 years. If this is recognized as the true interpretation of the results, and it seems a fair conclusion from the evidence presented, then any nursery selection based upon size of stock seedlings existing after the so-called variants are excluded, would seem to be valueless.

It should be remembered, however, that the total yield of the trees during the first five seasons after they came into bearing correlated with the trunk area of the stock seedlings gave a small positive correlation of $+0.135 \pm 0.035$. It may be that even this low correlation indicates a sufficient influence of seedling size to justify the discarding of the small seedlings before budding. A study of the annual tree yields of the crops for the period from 1925-26 to 1929-30 and a correlation of each with stock seedling size in 1921 as shown by area of trunk cross section gave the following data:

\begin{tabular}{|c|c|c|c|}
\hline Crop season & $\begin{array}{l}\text { Mean annual yield } \\
\text { per tree, in pounds }\end{array}$ & $\begin{array}{l}\text { Coefficient of varia- } \\
\text { tion, in per cent }\end{array}$ & $\begin{array}{l}\text { Coefficient of correla- } \\
\text { tion with } 1921 \text { seedlings }\end{array}$ \\
\hline 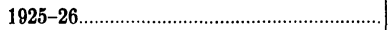 & $18.51 \pm 0.278$ & $41.37 \pm 1.235$ & $+0.291 \pm 0.033$ \\
\hline 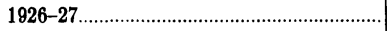 & $53.32 \pm 0.670$ & $34.62 \pm 0.987$ & $+0.160 \pm 0.035$ \\
\hline $1927-28 \ldots$ & $42.68 \pm 0.890$ & $57.42 \pm 1.894$ & $+0.147 \pm 0.036$ \\
\hline $1928-29 \ldots$ & $101.35 \pm 1.527$ & $41.50 \pm 1.232$ & $+0.157 \pm 0.036$ \\
\hline 1929-30 & $62.22 \pm 0.939$ & $41.59 \pm 1.235$ & $+0.072 \pm 0.037$ \\
\hline
\end{tabular}

A comparison of the coefficient of variation in yield for the different seasons shows no indication that the variation in tree yield is decreasing as the trees grow older. This is in marked contrast to the 
gradual decrease in the percentage of variation that took place in all tree size characters measured.

There was a fairly significant correlation in 1925-26, which became less in the succeeding years and in the last year of the five-year period was entirely insignificant.

The same population treated in another way by a direct selection based on the stock diameter of the seedlings indicates that the gain in yield during the period concerned was sufficient to justify a fairly severe selection. (See discussion on page 63.)

\section{Relation of Size of Budlings to Size of 8-Year-Old Orchiard Trees, as Shown by Trunk Area}

In table 6 the various statistical constants are given for the size of budling as shown by area of trunk cross section when 1 year old in the nursery, at the time of digging in the spring of 1922, as compared with the size of scion trunk of the orchard trees November 1, 1929, at the close of the eighth season of growth in the orchard.

In table 6 the data is divided on the basis of the grading of the seedlings at the seed bed into firsts and seconds according to size, and later at time of budding into normal and variant types. These segregations must be kept clearly in mind to understand the discussion. An examination of columns 1,2 , and 3 of this table shows that when the entire population is compared with the firsts only, and with seconds only, the mean size of the firsts is greater than that of the seconds. while also, the standard deviation is less for the firsts, than for the seconds. This seems natural since the seconds contain the larger proportion of the dwarfed variant types. The coefficient of variability of the three groups follows the same rank as the standard deviation. It is interesting to note that in each of the three groups the 1-year-old budlings show a much greater coefficient of variation than the 8-year-old trees.

The coefficients of correlation in which greatest interest centers are $+0.622 \pm 0.021$ for the entire population, $+0.411 \pm 0.037$ for the firsts, and $+0.743 \pm 0.025$ for the seconds. These correiations are sufficiently high in each case to be considered markedly significant. It is very evident that either with the entire population or with merely the firsts or the seconds when the variants are included, there is a strong probability that a large nursery tree will tend to produce a relatively large orchard tree and that a small nursery tree will tend to produce a small orchard tree. 


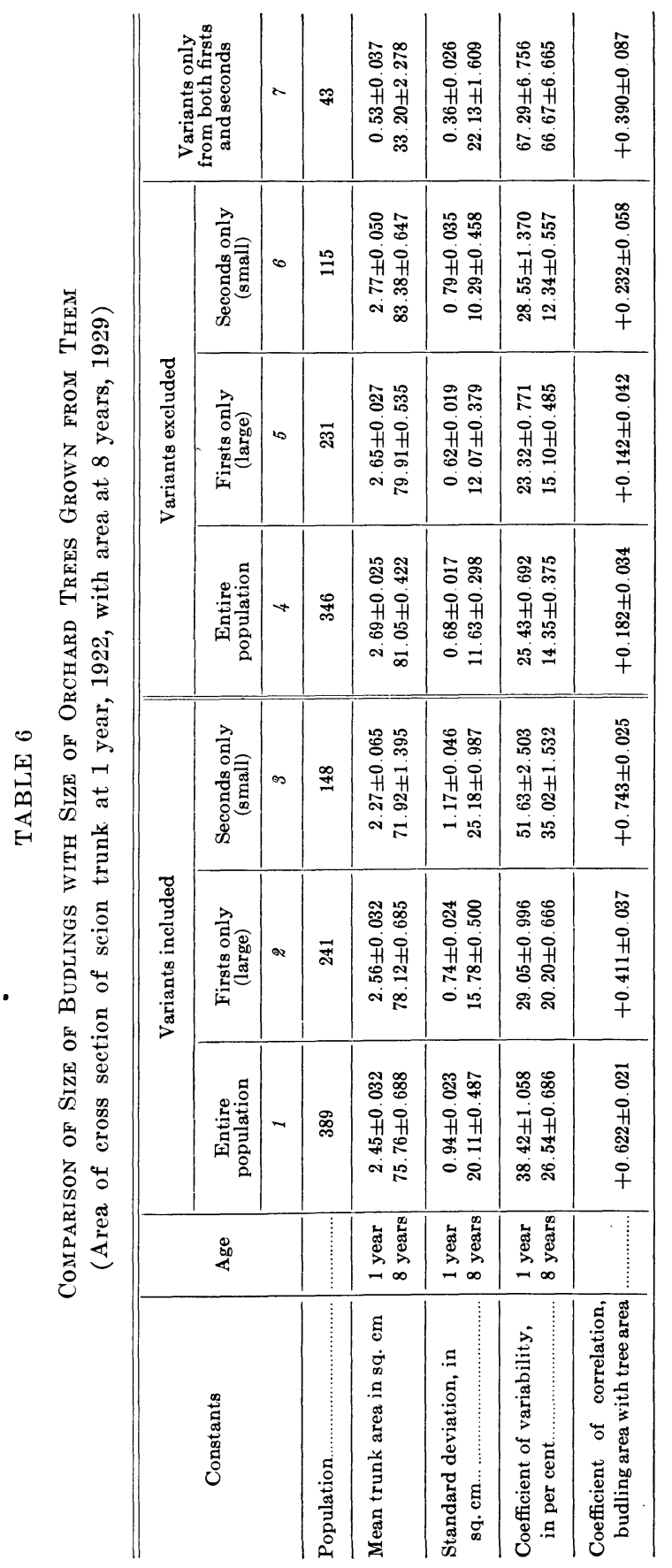


In view of the fact that the early study of the stock seedlings used revealed the presence of numerous variants, or types differing from the normal standard type of the population, it is important to carry the analysis further and determine what effect these variant types have had on the results. The second part of table 6 gives the same statistical constants for the same groupings of the population as those given in columns 1, 2, and 3, but with the trees known to be on variant stock seedlings excluded from consideration.

By comparing columns 4, 5, and 6 of table 6 it may be noted that when the variants are excluded the area of cross section of budling trunk of the seconds (i.e., the group grown on seedlings graded at the seed bed as seconds in size), at 1 year of age in the nursery gives the largest mean size $2.77 \pm 0.050 \mathrm{sq}$. $\mathrm{cm}$, while the mean for the firsts is slightly less, being $2.65 \pm 0.027 \mathrm{sq}$. $\mathrm{cm}$, and that for the entire population exclusive of variants is $2.69 \pm 0.025 \mathrm{sq} . \mathrm{cm}$, an intermediate figure. It is also interesting to note that the same relation of size exists at the end of the eighth growing season in the orchard when the means are for seconds, $83.38 \pm 0.647 \mathrm{sq}$. $\mathrm{cm}$; entire population, 81.05 $\pm 0.422 \mathrm{sq} . \mathrm{cm}$; and firsts, $79.91 \pm 0.535 \mathrm{sq} . \mathrm{cm}$.

The standard deviation for the trunk areas of the 1-year-old budlings is greater for the seconds than for the firsts, while after 8 seasons in the orchard the same population shows the standard deviation greater for the firsts than for the seconds.

The coefficient of variability for the trunk areas of the 1-year-old budlings is greater for the seconds than for the firsts but after 8 seasons this order is reversed.

The tendency of the seconds, as shown by the mean area of budling trunk when the variants are excluded, is to be rather larger than the firsts, and they also seem to show a slightly greater uniformity as indicated by a lower standard deviation and a smaller coefficient of variability.

It will be seen later that when the variants are excluded, the seconds are also slightly superior to the firsts as shown by a somewhat larger mean volume of top and total 5-year yield and by a lower standard deviation and coefficient of variability for each of these characters.

Even though this result is obtained with the exclusion of the variants, which were most numerous among the seconds, it is the reverse of what would generally have been expected.

As this result was obtained with two segregated portions of the same population, after the variants were excluded, the seedling root- 
stocks were doubtless almost wholly of apogamic origin, and thus approximately of the same genetic constitution. Apparently, therefore, it may be concluded that this slight superiority of the seconds is due to the favorable influence of the greater space available for their development owing to the high mortality among the variants which were most numerous in this group (see fig. 2, orchard 1-Z), or possibly to the slight detrimental effect caused by the first-grade seedlings, being somewhat too large when they were budded (see table $5)$. It does not seem probable that the difference is to be considered as significant.

The coefficients of correlation in these three groupings of the population with the variants exluded (columns 4,5 , and 6 of table 6 ), are for the entire population $+0.182 \pm 0.034$; for the firsts, +0.142 \pm 0.042 ; and for the seconds, $+0.232 \pm 0.058$. While these correlations are small and barely significant, they all show the general tendency of the large scions in the nursery to produce the large orchard trees and add to the evidence favoring this conclusion.

Statistical constants for the variants alone are given in table 6, column 7. The trees all average much smaller than those in the other groupings of the population, the mean size of 1-year budlings being only $0.53 \pm 0.037 \mathrm{sq}$. $\mathrm{cm}$ in comparison to $2.69 \pm 0.025 \mathrm{sq}$. $\mathrm{cm}$ for the entire population exclusive of variants. The 8-year-old variants had a mean size of $33.20 \pm 2.278 \mathrm{sq}$. $\mathrm{cm}$, while the population exclusive of variants had a mean size of $81.05 \pm 0.422 \mathrm{sq}$. cm. This illustrates very clearly the dwarfing effect that the variant seedlings produce in the scions grown on them and shows why the variants should be eliminated and not used as stocks. The variants also, as would probably be expected, exhibit a high standard deviation and coefficient of variation.

It will be noticed that the population of variants gave a correlation of $+0.390 \pm 0.087$ between nursery size and orchard size of tree. This perhaps has no practical bearing on the problem of nursery selection, as all the variants should certainly be discarded, but it does show that within this limited special population the size of the budling tends to influence the size of the budded tree, and evidence of such an influence, if it exists generally, is of interest.

In view of the general tendency of the percentage of variation and the degree of correlation with seedling size to decrease as the trees grow older, as shown by the comparison of size of stock seedlings in 1921 with the size of orchard trees in 1929 (table 4), and of budlings in 1922 with orchard trees in 1929 (table 6), it is desirable 
to know what occurs when size of budling is considered in relation to size of orchard trees at various periods. When the total population exclusive of variants is taken (346 trees), and the area of budling trunk when 1 year old at time of transplanting in 1922 is correlated with area of scion trunk of the orchard trees in 1924 when 2 years old, in 1927 when 6 years old, and in 1929 when 8 years old the coefficients of correlation are, for 1924, $+0.358 \pm 0.032$; for 1927, $+0.170 \pm 0.036$; and for $1929,+0.182 \pm 0.034$.

Evidently there is a decreasing correlation until the sixth year, when the trees apparently reach a condition approaching the normal variability of mature trees as the correlation in the eighth year is practically equal to that of the sixth year.

\section{Relation of Size of Budlings to Size of 8-Yeir-Old Orchard Trees, as Shown by Top Volume}

In the preceding section the correlations are given between the size of the budlings as indicated by area of cross section of scion trunk at time of transplanting, with the area of trunk of the orchard trees when 8 years of age and at intermediate periods. As any single measurement of size is subject to considerable variation and may not be a true index of the existing condition, it is desirable where possible to use other measurements of size as a check on the results. The volume in cubic feet of the tops of the trees in the same population was obtained in June, 1930, by the use of a standard fumigation tent, in order to use this index of size for comparison with trunk area and other data.

In table 7 statistical constants are given, similar to those of table 6 but comparing the size of the scion trunk of the 1-year budlings at the time of digging with the volumes of the tops of the same trees 8 years later in the orchard.

It will be seen from an examination of columns 1,2 , and 3 of this table that the mean size of top is greatest for the first-grade trees, least for the second grade, and intermediate for the entire population. The standard deviation and coefficient of variability are both less for the firsts than for the seconds. It cannot be stated whether or not the coefficient of variability decreases for volume of top as the trees grow older, as does the variability in area of scion trunk, because measurements of the volume of top were not taken for the young trees.

The coefficient of correlation between the trunk area of the young trees and the top volume of the 8-year-old orchard trees of +0.598 

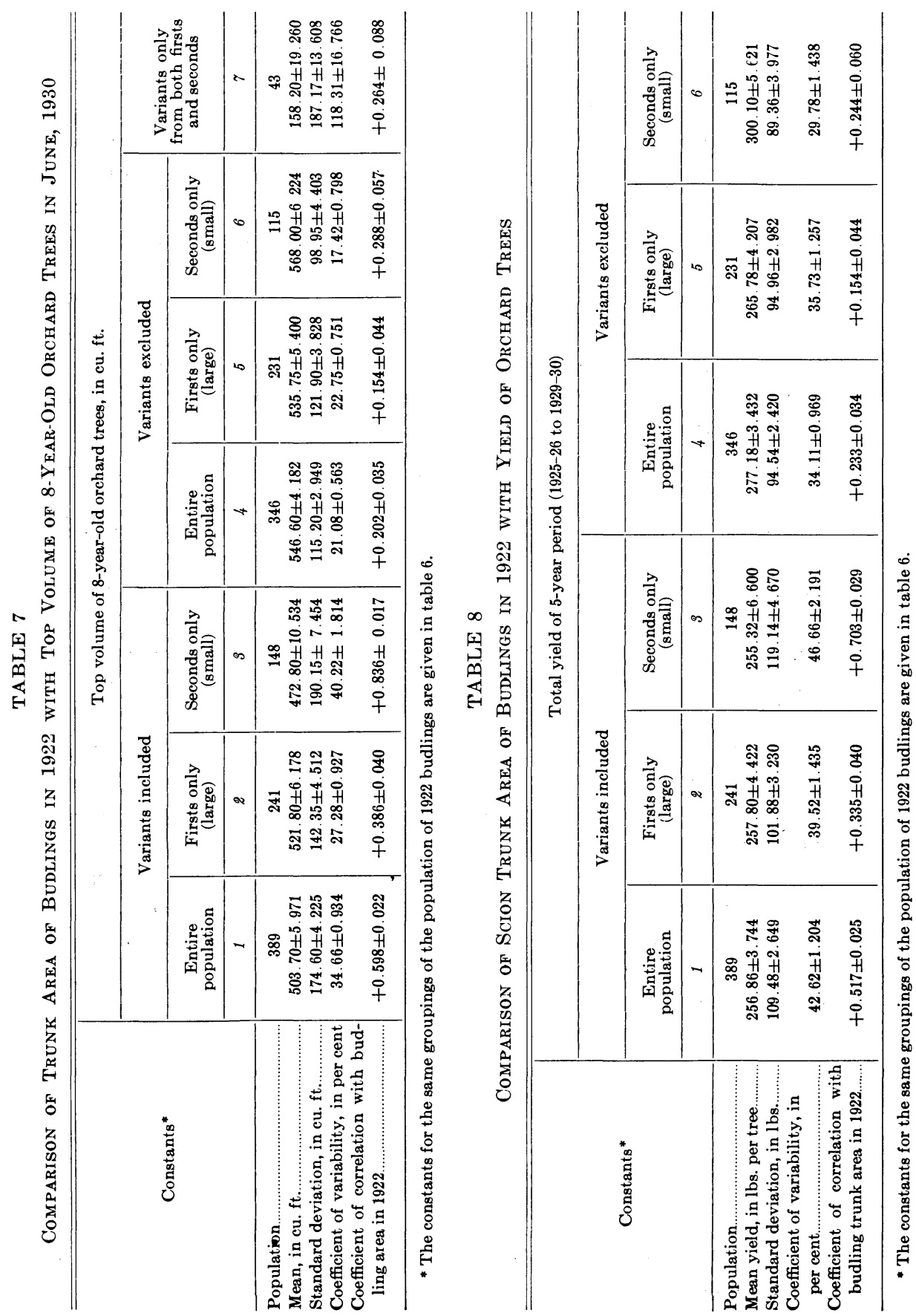
\pm 0.022 for the entire population, $+0.386 \pm 0.040$ for the firsts, and $+0.836 \pm 0.017$ for the seconds clearly indicates a strong tendency of the large nursery trees to produce a fairly high percentage of the large orchard trees and vice versa, as judged by top volume.

It is important also to consider the population with the variants excluded, as was done in the preceding section. When the entire population exclusive of variants is taken, and nursery size of budling trunk compared with volume of top at 8 years (columns 4,5 , and 6 , table 7 ) the combined population gives a coefficient of correlation of +0.202 \pm 0.035 , while the firsts give a correlation coefficient of +0.154 \pm 0.044 , and the seconds $+0.288 \pm 0.057$. It is thus shown again that the variants in the population (which are comparatively small in size in the early stages of growth, and in general have the effect of severely dwarfing the scions grown on them) are largely responsible for the high positive correlations shown in every case where any grouping of the population is taken with the variants included.

It will also be noticed in comparing populations of columns 4,5 , and 6 in table 7 (with variants excluded) that the seconds show, for top volume, a larger mean size and a smaller standard deviation and coefficient of variation than the firsts, a similar condition to that shown by the same populations when area of trunk of the orchard tree was used as the indicator of size. The differences, however, are comparatively small and probably have no significance.

It becomes increasingly evident from the data in this table that the segregation of the seedlings at the seed bed into firsts (large) and seconds (small) had no effect other than to segregate the largest proportion of the variants with the seconds.

The most important constant in this table is the correlation of $+0.202 \pm 0.035$ between the size of the budling trunks of the population without variants and the top volume of 8-year-old orchard trees. This indicates a persisting influence of budling size on orchard-tree size even after the variants are eliminated.

In order to show the relation existing between trunk size and volume of top measurements taken at about the same age, the areas of scion trunk taken in November, 1929, were compared with the measurement of top volumes, taken in June, 1930. Here when the entire population of 389 trees is considered the correlation is +0.923 \pm 0.006 , and when the variants are excluded the correlation is +0.817 \pm 0.013 . These high correlations indicate a very close relation between the size of the trunk and the size of the top at about the same period of development. 


\section{Relation of Size of Budlings to Yield of Orchard Trees}

While in this experiment there has been a general tendency for the large budlings to produce large orchard trees, it is of even more practical interest to know whether there is any direct correlation between the size of the budlings and the yield of the trees in the orchard. Interest centers in the production of fruit, and it matters little what relation one character bears to another unless in some way this relation bears on the quantity, quality, or grade of the fruit produced. The trees in this experiment have been producing some fruit since the year 1924-25 and the individual tree production has been recorded for a period of 5 years (1925-26 to 1929-30 inclusive). The yield of the first 5 years in the life of the orchard tree can scarcely be taken as indicating its final relative position as to yield, yet it will be granted that even the first 5 years of the fruiting period is important and is probably an indication of later performance. Table 8 gives the coefficients of correlation between area of cross section of scion trunk of the nursery trees and the total 5-year yield of the same trees, with the populations grouped as in the preceding tables.

It is of particular interest to note in table 8 that with the 389 trees considered in this experiment all segregations of the population studied give some degree of positive correlation between the original size of the nursery tree and the total yield produced. When the entire population is considered this correlation is found to be +0.517 \pm 0.025 ; for the firsts only, $+0.335 \pm 0.040$; and for the seconds only, $+0.703 \pm 0.029$. These correlations are sufficiently large to show conclusively that there is a very marked relation between the size of the nursery tree and its probable yield as an orchard tree when the variants are included.

When the variants are excluded from the population, these correlations become, for the entire population $+0.233 \pm 0.034$; for the firsts, $+0.154 \pm 0.044$; and for the seconds, $+0.244 \pm 0.060$. These are smaller and less significant correlations, but they do indicate a tendency for the large nursery trees (budlings) to produce highyielding orchard trees and vice versa, even after the variants have been excluded. They also emphasize the effect of the variants on yield.

It will also be noticed that populations 4,5 , and 6 , when the variants are excluded, give reversals in mean, standard deviation, and coefficient of variation between the different groups of firsts and seconds similar to those shown in tables 6 and 7 . 


\section{Changes in Interrelations of Size and Yield as Trees InCREASE IN AgE}

Attention has been directed in preceding sections to the decrease that gradually takes place in the range of variation and also in the coefficients of correlation of the trunk areas (cross section of trunk) of the seedlings in 1921 and of the budlings in 1922 compared with the orchard trees at different periods as the trees grow older. In order to obtain a clear picture of what is taking place, it is interesting to compare these figures with interperiod and interannual correlations. It is important to know whether the trees that push ahead rapidly and attain large comparative size, continue to maintain this larger size and possibly give larger yields as a result.

The data giving the relation of the early trunk area of the seedlings and budlings of the population exclusive of variants to the later trunk areas of the orchard trees is summarized for easy comparison in table 9 .

TABLE 9

Relation of Trunk Area of Seedlings and Budlings to Trunk Area of Trees in Later Years

(Population, exclusive of variants, 346 trees)

\begin{tabular}{|c|c|c|c|}
\hline Year & $\begin{array}{c}\text { Age, } \\
\text { years or seasons } \\
\text { of growth }\end{array}$ & $\begin{array}{l}\text { Coefficient of } \\
\text { variation, } \\
\text { in per cent }\end{array}$ & $\begin{array}{c}\text { Correlation } \\
\text { with } 1922 \text { budling } \\
\text { size }\end{array}$ \\
\hline 1921 seedlings................ & 3 & $33.05 \pm 0.934$ & $+0.549 \pm 0.026$ \\
\hline 1922 budlings & 1 & $25.43 \pm 0.692$ & \\
\hline 1924 trees (April).. & 2 & $18.43 \pm 0.488$ & $+0.358 \pm 0.032$ \\
\hline 1927 trees (September).... & 6 & $15.92 \pm 0.417$ & $+0.170 \pm 0.035$ \\
\hline 1929 trees (November) & 8 & $14.35 \pm 0.375$ & $+0.182 \pm 0.034$ \\
\hline
\end{tabular}

An examination of these data shows the rather rapid smoothing out of the variation and the decrease of the correlation between original and final size. This might lead to the conclusion that there is no permanent relation of size and that there might possibly be a fluctuation in different years. Interperiod correlations, however, show that there is apparently an increasingly stronger correlation from one period to the next as the trees grow older. This is indicated by the following data, consisting of correlations between size as indicated by area of trunk section for different periods, for the population exclusive of variants (346 trees):

Correlation coefficient

1922 budlings with 1924 trees $+0.358 \pm 0.032$

1924 trees with 1927 trees $+0.618 \pm 0.023$

1927 trees with 1929 trees $+0.781 \pm 0.014$ 
It will be seen that the correlation coefficients increase very materially as time goes on. These figures tend to confirm the results of Sax and Gowen (1923), Collison and Harlan (1930), and others, as to the permanency of size relations in orchard trees.

It has been found that the original trunk area of the budlings, exclusive of variants, correlated with the 1929 scion trunk area of orchard trees gave only the low correlation of $+0.182 \pm 0.034$, and that the seedling trunk areas at the time of budding when compared with 1929 seedling trunk areas gave a negative correlation of -0.054 \pm 0.032 , while during the same series of years the interperiod correlations reached the relatively high positive coefficient of $+0.781 \pm 0.014$. From this it would seem that the high degree of correlation exhibited in the later periods of growth is most likely due to some other influence than variations in the rootstocks. It would appear probable that it is caused by some more or less permanent and continuously acting environmental difference.

In the studies of Parker and Batchelor (1932) it was found that tree size as shown by trunk cross section compared with tree yield in the same year gave gradually increasing correlations during the period when the trees were from 6 to 10 years of age. These correlations, for the respective years, were $+0.109,+0.233,+0.247$, +0.278 , and +0.322 . The population of 346 trees with variant types eliminated, which is under consideration in the present discussion, gave a correlation of $+0.257 \pm 0.034$ between 1927 trunk area and with 1927 tree yields; and a similar comparison in 1929 gave a correlation of $+0.261 \pm 0.033$.

The experiment has not been under way long enough to afford opportunity to obtain interannual yield correlations that can be considered of very great value in the analysis of conditions. Yields have been recorded for 5 years, but those for the first two years of this period, when the trees were 4 and 5 years old respectively, were too small and variable to be given much consideration. For the next 3 fruit years, when the trees were approximately 6,7 , and 8 years old, the mean yields, coefficient of variability, and correlation coefficients, were as follows :

\begin{tabular}{|c|c|c|c|}
\hline Year & $\begin{array}{l}\text { Mean yield } \\
\text { per tree }\end{array}$ & $\begin{array}{l}\text { Coefficient of } \\
\text { variability }\end{array}$ & $\begin{array}{c}\text { Correlation with yield } \\
\text { of preceding year }\end{array}$ \\
\hline $1927-28$. & $\begin{array}{c}\text { pounds } \\
42.68 \pm 0.890\end{array}$ & $\begin{array}{c}\text { per cent } \\
57.42 \pm 1.893\end{array}$ & \\
\hline $1928-29 .$. & $101.35 \pm 1.527$ & $41.50 \pm 1.232$ & $+0.724 \pm 0.018$ \\
\hline $1929-30 \ldots$ & $62.22 \pm 0.939$ & $41.59 \pm 1.235$ & $+0.532 \pm 0.026$ \\
\hline
\end{tabular}


The decrease in the coefficient of variability in the last two years (1928-29 and 1929-30) might be taken as indicating that the differences in yield between the various trees have gradually smoothed out as the trees grew older. The variability in preceding years, however, as given on page 39 , does not support this assumption.

\section{Suggestive Results from this Experiment}

One of the outstanding features of this experiment is the uniformity of the results obtained in comparing budling and orchardtree size regardless of the measure used in the calculations. Within this lot of 389 trees, the coefficients of correlation obtained between area of cross section of trunk of the budlings and area of cross section of trunk, volume of top, and total yield of the 8-year-old orchard trees, were of about the same value for each segregation of the population; they differed little more than would be expected from the unavoidable errors of measurement. The conformity of these results appears to the writer to be so striking and important that the coefficients of correlation for the various measurements and segregations of the population are brought together in table 10 (cols. 3, 4, and 5) where they can be more easily compared. In column 2 of this table the same data are also given for nursery seedlings correlated with 1-year budling size, though these are naturally very different, and are to be considered only as showing the relation in size between the seedlings and budlings of the different groups.

\section{TABLE 10}

Coefficients of Correlation between Size of Nursery Trees and Size of Orchard Trees Grown from Them as Shown by Area of Scion

Trunk, Volume of Top, and Total 5-Year Yield

\begin{tabular}{|c|c|c|c|c|}
\hline Population & $\begin{array}{c}\text { Trunk area of } \\
\text { seedlings, 1921, } \\
\text { with 1-year bud- } \\
\text { lings, 1922 }\end{array}$ & $\begin{array}{l}\text { Trunk area of } \\
\text { 1-year budlings } \\
\text { with trunk area } \\
\text { of 8-year trees }\end{array}$ & $\begin{array}{l}\text { Trunk area of } \\
\text { 1-year budlings } \\
\text { with top volume } \\
\text { of } 8 \text {-year trees }\end{array}$ & $\begin{array}{c}\text { Trunk area of } \\
\text { 1-year budlings } \\
\text { with total 5-year } \\
\text { yields }\end{array}$ \\
\hline 1 & 2 & 3 & 4 & 5 \\
\hline 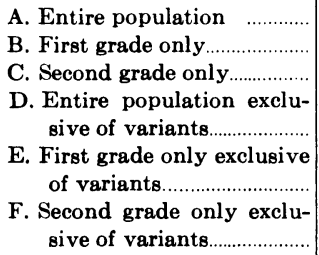 & $\begin{array}{l}+0.736 \pm 0.016 \\
+0.663 \pm 0.025^{*} \\
+0.823 \pm 0.018^{*} \\
+0.549 \pm 0.026 \\
+0.589 \pm 0.029^{*} \\
+0.545 \pm 0.045^{*}\end{array}$ & $\begin{array}{l}+0.622 \pm 0.021 \\
+0.411 \pm 0.037 \\
+0.743 \pm 0.025 \\
+0.182 \pm 0.034 \\
+0.142 \pm 0.042 \\
+0.232 \pm 0.058\end{array}$ & $\begin{array}{l}+0.598 \pm 0.022 \\
+0.386 \pm 0.041 \\
+0.836 \pm 0.017 \\
+0.202 \pm 0.035 \\
+0.154 \pm 0.044 \\
+0.288 \pm 0.057\end{array}$ & $\begin{array}{l}+0.517 \pm 0.025 \\
+0.335 \pm 0.040 \\
+0.703 \pm 0.029 \\
+0.233 \pm 0.034 \\
+0.154 \pm 0.044 \\
+0.244 \pm 0.060\end{array}$ \\
\hline
\end{tabular}

* These correlations are not given elsewhere. 
A comparison of the items in each of the lines of this table will indicate very clearly the great uniformity exhibited in each segregation of the population for each character measured. It seems that this must be interpreted as strong confirmation that, with this population, under the conditions of the experiment, the measurements recorded and the constants derived from them must be considered as fairly accurate.

It seems logical to conclude that, if an entire population including variants is considered. where uniform buds of a scion variety have been used as under the conditions of this experiment, the chances are strong that a large budling or nursery tree will tend to produce a relatively large, high-yielding orchard tree, and that a small budling is most likely to produce a relatively small and low-yielding orchard tree.

It seems clear that this effect is largely, but not entirely, due to the fact that the great majority of the small low-yielding orchard trees are such because they have been grown on variant, off-type stocks, and that at least the great majority of such variants in the seedling stocks in the population studied, could be recognized in the nursery by a careful observer, and eliminated.

It is of primary importance to note that the great majority of these variant types were found among the second-grade or small seedlings and would have been largely eliminated by a selection based on size when they were dug from the seed bed. It should also be noted that a selection of budlings based on size would have eliminated most of the variants. That the elimination of these variant types is of first importance cannot be doubted.

The analysis of the data also shows that in the population remaining after the variants have been excluded, there is still a small degree of correlation between budling size and the size and yield of orchard trees at 8 years of age. This correlation in the reduced population is still large enough to indicate a tendency for the large selected budling trees to give the better results.

In view of the fact that the second-grade trees, when the variants were excluded, gave a slightly larger mean size after 2 years in the nursery and also after 8 years in the orchard than did the first-grade trees, it may be concluded that the segregation into first and secondgrade seedlings at the seed bed, based on size, did not accomplish anything other than to place the variants mainly in the second grade. It was these dwarfed, variant types that accounted also for the strong correlation between budling size and orchard size, when the entire 
population was considered. It would appear that the seedlings in the seed bed were grown under such crowded conditions that their size is not a true indication of their inherent vigor, other than that the variants are mainly weak and thus small. Sax (1928) found the same to be true with apple seedlings, and states that "The size of the seedling as it comes from the wholesale nursery has little or no relation to the size of the 1-year-old nursery tree. Large seedlings did not produce larger whips than small seedlings. Evidently the size of a 1-year-old seedling as commonly grown, is so much influenced by crowding and other environmental factors that size is no indication of its hereditary vigor." After the seedling apple stocks have grown under nursery conditions with equal spacing for a year and reach the age for budding, their size was found by Sax (1924) to be a significant indication of their future growth, and he states "Correlations were obtained between size of the French crab seedlings and the size of the nursery trees grown on these seedling roots. The correlations between size of seedling and size of the one-year whips was found to be $0.36,0.38,0.26$, and 0.43 , respectively, for the four varieties, McIntosh, Ben Davis, Delicious, and Northern Spy. The correlation between seedling size in the fall of 1922 and the size of the 2-year nursery trees in 1924, was found to be $0.42,0.39,0.38$, and 0.45 for the above varieties. In all cases the size of seedling root seemed to have slightly more influence on the nursery trees as they became older."

Sax's results indicating that "the size of the seedling root seemed to have slightly more influence on the nursery trees as they became older" do not seem to hold in citrus. In the citrus experiment under consideration, the correlation between budling size and size of scion trunk of orchard trees gradually becomes smaller as the trees grow older, at least up to the close of the 1929 season when the trees were 8 years old, and the coefficients of variation gradually become less in the population as a whole. Sax's results were apparently obtained with young trees growing continuously in the same place and it seems probable that the increased correlations observed are to be interpreted as mainly due to soil variations just as with the increased interperiod correlations obtained by the writer.

It should also be remembered in comparing these results that apple seedlings because of cross-pollination are likely to be highly variable, but that citrus seedlings because of apogamy are likely to be much less variable. 
In the case of the reactions of the French crab seedlings with which Sax's results were obtained, probably a considerable number of the variant seedlings that would give extreme dwarfing had been eliminated at the wholesale nursery; and yet the results show that, as judged by size at the end of a year in the nursery, the seedlings gave a fairly significant coefficient of correlation.

With cherries, Burkholder and Green (1929) found that with a population of 1,191 Mahaleb cherries budded with Montmorency, seedling size at time of budding correlated with size of budlings at end of 1 year's growth gave a correlation coefficient of $+0.685 \pm 0.0158$. The same correlation for the citrus population of 387 trees under consideration was $+0.736 \pm 0.016$ (see table 3 ).

In the study of two apple orchards of different varieties over a period of 20 years, Collison and Harlan (1930) found that the trees maintain their comparative size relations to a marked degree, but they also found that "variability in both yield and diameter growth becomes less with increasing age of tree." These results were obtained with orchard trees of considerable age and size when the records began, while in the present experiments the study started with the planting of the seed, and has continued only to the eighth vear in the orchard. It is significant, however, that with both apples and citrus the variation shown during the first part of the period persists. As is pointed out elsewhere, buds are variable in time of starting, and thus in the early stages of budling growth the range in comparative size is very great; but it gradually becomes less evident as the budling tops grow older. One of the factors contributing to the increased variability of young trees is believed to be the distinct shock which the rootstock suffers at the time of budding and topping, which results in a great lack of balance between the root and top. The normal balance is more slowly regained if the rootstock is large.

Relative to the coefficient of correlation between budling size in 1922 and the size of the orchard trees at different periods of growth, it will be seen that this decreases from $+0.358 \pm 0.032$ in 1924 to $+0.170 \pm 0.035$ in 1927 , and in 1929 is $+0.182 \pm 0.034$, an insignificant increase over that for 1927. The figures would suggest that the coefficient of correlation may decrease for a certain period until an equilibrium is established between the various factors affecting growth. 


\section{EFFECT OF BUDLING SIZE ON THE SIZE AND YIELD OF ORCHARD TREES IN A SELECTED POPULATION ON SWEET-ORANGE STOCKS ${ }^{13}$}

Washington Navel orange trees on sweet-orange stocks grown in the fertilizer experiments of the Citrus Experiment Station furnish interesting data on the continued maintenance of comparative size. This orchard contains 1,506 normal Washington Navel orange trees that were planted in the spring of 1917 . (See page 15 for statement. of early history of these trees.)

These trees were grown on sweet-orange stocks taken from an especially uniform, good seed bed from which at the time of digging some 10 per cent of the total number of seedlings were discarded as being too small to plant. The seedlings chosen were grown in a nursery at the Station, given uniform treatment, and budded with carefully chosen buds from good trees of known performance record. At the time of budding all noticeably small and off-type seedlings were also eliminated. When the budlings were transplanted into the permanent experimental orchard, the large ones only were chosen for the planting. No exact record was made of the number of small and medium-sized trees that were discarded, but the writer assisted in choosing the trees for the planting and estimated that about 30 per cent of the total number of budlings were discarded as being too small to meet the requirements of size. This selection probably eliminated all or nearly all of the trees that were propagated on variant seedlings. Extra care was taken to treat these trees as uniformly as possible during the period of 10 years after planting, before the differential fertilizer treatments were ápplied.

The trunk measurements recorded were made first in 1918, approximately 1 year after the trees were planted in the orchard. They have been measured at regular intervals since that time, and the yield has been recorded annually.

Table 11 gives certain statistical constants obtained from a study of the data of this orchard. The data for area of cross section of scion trunk in 1918 is compared with that of the area of scion trunk

13 The measurements of size and yield used in the correlations reported here were taken from the records of the fertilizer experiments of the Citrus Experiment Station, and are used with the kind permission of Drs. L. D. Batchelor and E. R. Parker. 
in 1926. and also with that of the average total yield of each tree during a period of 7 years, from the crop of 1920-21 to that of 1926-27 inclusive.

TABLE 11

Comparison of Size of 1-Year-Old Washington Navel Orange Trees on Sweet-Orange Stocks with Size and Yield of the Same Trees After 9 Growing Seasons

(A selected population of 1,506 from which variant seedling stocks had been removed)

\begin{tabular}{|c|c|c|c|}
\hline Statistical constants & $\begin{array}{l}\text { Area of scion trunk } \\
\text { at } 1 \text { year, } 1918\end{array}$ & $\begin{array}{l}\text { Area of scion trunk } \\
\text { at } 9 \text { years, } 1926\end{array}$ & $\begin{array}{c}\text { A verage total yield } \\
\text { per tree during } 7 \text { years. } \\
\text { Crops of } 1920-21 \\
\text { to } 1926-27\end{array}$ \\
\hline 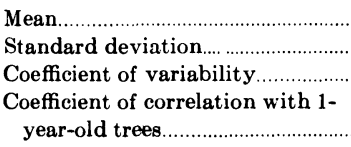 & $\begin{array}{c}6.23 \pm 0.021 \text { sq. cm } \\
1.20 \pm 0.015 \text { sq. cm } \\
19.13 \pm 0.244 \text { per cent }\end{array}$ & $\begin{array}{l}127.18 \pm 0.311 \text { sq. cm } \\
17.89 \pm 0.220 \text { sq. cm } \\
14.07 \pm 0.176 \text { per cent } \\
\\
+0.158 \pm 0.017\end{array}$ & $\begin{array}{l}776.38 \pm 2.318 \text { lbs. } \\
133.19 \pm 1.638 \text { lbs. } \\
17.15 \pm 0.217 \text { per cent } \\
\\
+0.229 \pm 0.016\end{array}$ \\
\hline
\end{tabular}

An examination of the data in table 11 shows that the size of the trees became slightly less variable as they grew older, the coefficient of variability for the 1-year-old trees being $19.13 \pm 0.244$ per cent in comparison with $14.07 \pm 0.176$ for the 9 -year-old trees. The correlation coefficient of $+0.158 \pm 0.017$ between the size at 1 and 9 years of age, is small but significant and indicates a general tendency for the trees to retain the relative position of size held at the time of the measurement when the trees were only 1 year old.

When the average yield per tree during the 7-year period is compared with the size of the 1-year-old trees, as shown by area of trunk section, a correlation coefficient of $+0.229 \pm 0.016$ is obtained.

In this population of Washington Navels on stocks of sweet-orange seedlings, the degree of selection practiced would correspond very closely to that of the population of the preceding experiment with variants excluded, the constants for which are given in column 4 of tables 6,7 , and 8 . It is interesting to note how very close together the corresponding constants are, indicating that the possible scionic influence due to size of stock seedlings selected is likely to be about the same with sweet as with sour stocks. To show more clearly the similarity in magnitude of the corresponding constants for the two populations, table 12, in which the two populations are distinguished by their stocks, will be of assistance.

Chief interest in the data assembled in table 12 centers in the fact that for the two populations on sour stock and sweet stock the 
coefficients of correlation between size of budling and size of orchard tree $(+0.182 \pm 0.034$ and $+0.158 \pm 0.017$ respectively $)$, and between the size of budling and total yield $(+0.233 \pm 0.034$ and +0.229 \pm 0.016 respectively) are so nearly alike. In view of this fact it would seem probable that these degrees of correlation may be taken as approximately the normal correlation to be expected with similarly selected citrus trees under such conditions on either sweet or sour-orange rootstocks.

\section{TABLE 12}

Comparison of Statistical Constants for Two Populations of Washington Navel Oranges with Approximately Equal Degree of Seldection

(Variants Excluded), but One on Sour Stock and THE OTHER ON SWEET STOCK*

\begin{tabular}{|c|c|c|c|c|c|}
\hline \multirow[b]{2}{*}{ Stock } & \multicolumn{3}{|c|}{ Coefficients of variability } & \multicolumn{2}{|c|}{ Coefficients of correlation } \\
\hline & $\begin{array}{l}\text { Trunk area of } \\
\text { budlings }\end{array}$ & $\begin{array}{l}\text { Trunk area of } \\
\text { orchard trees }\end{array}$ & $\begin{array}{l}\text { Yield of } \\
\text { orchard trees }\end{array}$ & $\begin{array}{l}\text { Trunk area } \\
\text { of budling with } \\
\text { trunk area of } \\
\text { orchard trees }\end{array}$ & $\begin{array}{l}\text { Trunk area } \\
\text { of budling with } \\
\text { total yield of } \\
\text { orchard trees }\end{array}$ \\
\hline Sour & $\begin{array}{c}\text { per cent } \\
25.43 \pm 0.692\end{array}$ & $\begin{array}{c}\text { per cent } \\
14.35 \pm 0.375\end{array}$ & $\begin{array}{c}\text { per cent } \\
34.11 \pm 0.969\end{array}$ & $+0.182 \pm 0.034$ & $+0.233 \pm 0.034$ \\
\hline Sweet & $19.13 \pm 0.244$ & $14.07 \pm 0.176$ & $17.15 \pm 0.217$ & $+0.158 \pm 0.017$ & $+0.229 \pm 0.016$ \\
\hline
\end{tabular}

* The budlings and orchard trees on sour stock were in each case 2 years younger than those on sweet stocks.

It will also be seen from a study of table 12 that there is a rather marked degree of difference in the coefficient of variability of the budling trunks ; for the population on sour stock it is 25.43 per cent, while for the sweet stock it is 19.13 per cent. This difference is readily understood when it is remembered that the budlings on sour stock were measured at the end of 1 year after the buds were inserted, while those on the sweet stock were not measured until 3 years after the budding. As observed above, the coefficient of variation of young budlings, which is at first very high, normally decreases very rapidly through several years.

It will be noticed also that the coefficient of variability in the yield of the orchard trees on sour orange (34.11 per cent), is about double that of the trees on sweet stock (17.15 per cent). This difference in range of variability is understandable in view of the fact that the yields on the sour-stock trees were for a shorter period and from younger trees, where a higher range of variability is to be expected. 


\section{RESULTS FROM PRACTICAL ORCHARD EXPERIMENTS}

Evidence from field experiments is usually somewhat faulty because it is limited to small populations, and supplementary information obtained from orchard plantings may sometimes be of very great value. Such evidence bearing on the problem under consideration was furnished by a Valencia orange grove of 60 acres on sour-orange stocks on the San Marino ranch near Pasadena. ${ }^{14}$ In the planting of this grove the nursery trees used were grown and budded on the ranch, and many more trees were grown than were required for the prospective planting. All were budded from selected trees on the ranch.

It was at first intended to plant only 20 acres with these trees, and the largest and best trees in the nursery were chosen and used for this planting. Since many good treas remained after the planting of the first 20 acres, it was decided to plant a second 20 acres, and the nursery was subjected to a second selection of the best trees remaining. These were planted in an orchard adjoining that made with the trees of the first selection. As a number of small and apparently healthy trees still remained in the nursery, a third tract of about the same size was planted with them.

These trees were thus planted in three sections of the same orchard at slightly different times, but they were all on seedlings of the same age, grown in the same nursery, and budded at the same time with buds from the same source.

The writer made a careful study of the three sections of this grove in 1922 when the trees were 5 years old. That portion of the grove planted with the largest nursery trees (first selection) had made a fine growth. The trees were remarkably uniform in size, and were large, vigorous, and fruitful, as shown by the mature crop on the trees at the time the examination was made and the young fruits set for the next year's crop.

The portion of the grove planted with intermediate-sized trees (second selection) had made a fair growth, but the trees were much smaller and less fruitful than those in that part of the orchard planted with large trees. While this portion of the orchard was fairly uni-

\footnotetext{
14 The details relative to the planting of this orchard and the results obtained were described by the writer in an earlier paper (Webber, 1922). Unfortunately this grove was destroyed when 8 years of age to make room for city development.
} 
form, it contained a considerable number of undersized trees. Very few of the largest trees were as large as the smallest in the part of the orchard planted with large trees.

The portion of the orchard planted with the small trees was highly variable in tree size and growth and was much inferior in size and yield to either of the other two plantings.

In 1924 when the trees in this orchard were 7 years old, a study of the three sections was made by Mr. Glenn C. Nay, a graduate student of the University of California, working under the writer's direction. Comparable blocks containing 100 trees each were chosen in each section and measurements made of height of tree, diameter of top, circumference of scion trunk, and circumference of stock trunk. A summary of these data is given in table 13.

TABLE 13

Average Measurement's of 7-Year-Old Trees in Blocks Planted with Large, Medium, and Small Budlings; San Marino Ranch, Pasadena, California

\begin{tabular}{|c|c|c|c|c|c|}
\hline Grade of budlings & Population & $\begin{array}{l}\text { Average } \\
\text { height of } \\
\text { tree }\end{array}$ & $\begin{array}{l}\text { Average } \\
\text { diameter of } \\
\text { tree top }\end{array}$ & $\begin{array}{c}\text { Average } \\
\text { circumference of } \\
\text { scion trunk }\end{array}$ & $\begin{array}{c}\text { Average } \\
\text { circumference of } \\
\text { stock trunk }\end{array}$ \\
\hline I Large & 100 & $\begin{array}{l}\text { feet } \\
8.8\end{array}$ & $\begin{array}{l}\text { feet } \\
8.7\end{array}$ & $\begin{array}{c}\text { inches } \\
14.2\end{array}$ & $\begin{array}{c}\text { inches } \\
15.1\end{array}$ \\
\hline 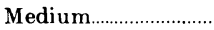 & 100 & 7.7 & 6.8 & 10.9 & 11.4 \\
\hline 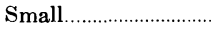 & 100 & 6.7 & 5.9 & 10.4 & 11.0 \\
\hline
\end{tabular}

It does not seem probable that the variation in soil, buds, or bud unions could be responsible for the differences exhibited by these three sections of the same grove. It is difficult to escape the conclusion that they were primarily due to the differences in the size of the nursery stock selected for the planting. Since uniformily good buds were used it seems likely that the most important variable was concerned with size and type of the rootstock seedlings.

Several other orchards have been examined that furnish similar suggestions, but, as the data is in agreement with the one cited and with the results of the experimental plantings herein discussed, they will not be described here. 


\section{GENERAL DISCUSSION OF RESULTS}

Ever since the early beginnings of agriculture, propagation from the best individuals has been more or less generally practiced. This practice and general understanding was erystallized by Darwin into the principle of "improvement by selection." Theories concerning the type of variation on which selection acts, have changed greatly in recent years; but the fact that selection of the best individuals as parents for propagation maintains or improves a race or breed, has not been and probably cannot be, questioned. No scientific principle on which agricultural practices are based would seem to be more surely established than this.

The selection of rootstocks, however, has seldom been practiced further than to choose the type or species giving the best results generally. The results presented in this study do not approach the question of what type or species is the best stock for a certain fruit variety on a certain soil, but furnish evidence relative to the importance of selecting the best individuals for stocks within the species or variety.

\section{Size as a Measure of Superiority}

The question in considerable measure hinges on what constitutes the best individuals. Are the largest and most vigorously growing seedlings to be considered the best or might not smaller, more slowgrowing types prove superior? It might well be that some stock type normally of slower growth or one of more rapid, vigorous growth would prove superior to those now used. The results, however, do tend to prove that whatever type is used, the normal, vigorous individuals of that type should be chosen and the weaklings and variants discarded.

Throughout the discussion, emphasis has been placed on the importance of large size of tree, and yet the question might be raised as to whether large size of tree is correlated with high yield, and whether after all, large size of tree is important. This emphasis seems to be warranted since in the present study, size of tree has been found to be positively correlated with yield. It will be remembered that comparisons between trunk area and yield in the years 1927 and 1929 gave correlations of $+0.257 \pm 0.034$ and $+0.261 \pm 0.033$, respectively. Parker and Batchelor (1932) also obtained similar correlations between size and yield during five different years. These 
correlations, as Parker and Patchelor point out, are positive and significant and it seems that we may safely conclude that under ordinary conditions where citrus trees of the same age have been treated similarly, the largest trees will most commonly be the highest producers.

In considering different varieties on different stock species, however, a different size standard would doubtless be required. If one were using a dwarfing stock in order to insure the production of trees below standard size it might be considered that the largest stock seedlings and the largest budlings should be discarded in order to insure dwarfing. The writer believes that this would be an erroneous policy; that whatever type of stock is used variants would be produced that would give still smaller trees-trees so weak that they would be unsatisfactory; and thus that even when a dwarfing stock is chosen, the strongest and best individuals of this stock should be used.

\section{The Basis of Citrus Rootstock Selection}

Evidence Indicating Effectiveness of Selection.-As pointed out in the introduction of this paper, the importance of selection within the type in connection with rootstocks used for propagation had been disregarded and apparently largely overlooked prior to the appearance of the writer's first publications on this subject (1920 and $1920 a)$. The first experiment in testing the results obtained by choosing large, medium, and small budlings from the same batch of nursery trees indicated in general that the various sizes tended in considerable degree to retain the same relative size throughout a period of 12 years. Out of the 9 plots of three varieties, only 1. plot, that of small Valencias, proved an exception.

In this experiment the correlations of nursery budling size with trunk area and top volume of 12-year-old orchard trees were positive and fairly large, for all three varieties (table 2). Similar correlations between size of nursery budlings and total 6-year yields were for Marsh grapefruit moderately large $(+0.410 \pm 0.085)$, for Washington Navel small, and for the Valencia orange, due to the exception in the plot of small trees, slightly negative.

In the data presented from a population of 389 trees in a second experiment, the correlation between the size of nursery seedlings at the time of budding and the size of the budlings when 1 year old, was positive and large (table 3 ). The correlation coefficients between the size of 1-year-old nursery budlings as indicated by area of trunk 
cross section, and the trunk area, top volume, and 5-year yields per tree of the 8-year-old orchard trees grown from them in the same experiment, were all positive and sufficiently large to be very significant (tables 6, 7, and 8). It is evident, therefore, that with citrus a severe selection based on size should be made, either of the stock seedlings or of the budlings before they are transplanted to the orchard or possibly of both. The determination of the best method of selection to pursue, however, is complicated by the presence of variant types among the stock seedlings.

The number of these variant types present differs mainly in accordance with the percentage of sexually produced embryos developed by the particular stock type used. In ordinary lots of sour or sweet-orange seedlings they would probably amount to from 15 to 25 per cent of the total number of seedlings produced.

The seed-bed stock in this experiment, after discarding the smallest seedlings to the extent of about 10 per cent of the total population was graded into first grade (large) and second grade (small). At the time of the critical study and numbering of these seedlings, just before they were budded, as described on page 24, it was found that much the largest number of variants were among the seedlings classed as second grade. By the discarding of all of the second-grade seedlings, 81.18 per cent of all of the evident variants would have been thrown out, but 18.82 per cent of the variants would still have remained among the lot graded as firsts, and these could only be detected after the seedlings had been grown a year or two in the nursery.

The problem of improving nursery stock depends primarily on the elimination of these variant types so far as they can be recognized, and, apparently, secondarily on the elimination of a certain percentage of the remaining seedlings that are below average vigor.

In a preceding section of this paper it was pointed out that in the seed bed, under the severe crowding that occurs as seed beds are ordinarily grown, the size of the seedlings of normal type apparently cannot be taken as an indication of their growth rate and character. Their size is probably due in large measure merely to the incident of the varying size of the embryo, promptness or delay of germination, and their location in the seed bed. Thus if all of the small seedlings up to from 45 to 50 per cent of the total population (the second-grade seedlings, paragraph above) are eliminated at the seed bed, perhaps 80 to 85 per cent of all the variants would be removed; but a considerable number of good stock seedlings would also be discarded. 
Meanwhile from 15 to 20 per cent of the variants would remain with the selected large seedlings, and these can only be detected later in the nursery where they are given sufficient space to develop and exhibit their characteristics.

It seems evident, therefore, that a single selection at the time of digging the seed bed, sufficiently severe to eliminate the greater part of the variants, would be impractical, as some variants would not be detected and eliminated, and the destruction of good seedlings would be too great. The elimination should probably not be greater than 25 to 35 per cent of the total number of seedlings; this will take out all of the seedlings so small as to be difficult to transplant and also a considerable proportion of the variants.

The further selection to eliminate the variants apparently should then be made in the nursery just before the budding begins. At this time, if the seedlings have been allowed to grow until they have reached a diameter averaging about $3 / 8$ inch, which when 1 -year-old seed bed stock is used, will usually require 2 years (or 2 growing seasons) in the nursery, they will have had sufficient time to exhibit more fully their true characters. The small and variant types can be detected at this time and not budded. Such roguing should also eliminate the individuals of normal type that are too weak to produce good trees.

The examination and selection at this period is probably to be considered as the most critical and important; for it is the only period when the top characters of the stock seedlings can be seen. It is also done before the expense of budding has been added to the value of the tree. Attention should be directed to the fact that nurseries throughout California are now very generally budding younger and smaller seedlings than those used in this experiment or than were commonly used by nurserymen a few years ago. The variations in size and type in the younger seedlings cannot be so easily recognized and the elimination of variants is thus more difficult.

When the small seedlings have been removed at the seed bed and all evident variants have been eliminated in the nursery, the data from two different experimental populations, one on sour stocks and one on sweet stocks, indicate that small positive correlations exist between size of budlings, as shown by area of trunk cross section, and size and yield of 8 and 10-year-old orchard trees (tables 6, 7, 8 , and 11). These rather small correlations may leave one in doubt as to whether any further selection would be effective. 
It must, furthermore, be remembered that in comparing the size of seedlings at the time of budding with the size of budlings and of orchard trees at various ages when the variants were eliminated, the correlation, which with 1-year budlings was fairly large, gradually decreased to nothing with 8-year-old trees (table 4). The size of the stock trunk at time of budding correlated with size of stock trunk and also with top volume of the orchard trees after 8 years gave small but not significant negative correlations.

With yield, however, the case may be somewhat different. The area of seedling stock trunk at time of budding correlated with total 5 -year yield gave a coefficient of $+0.135 \pm 0.035$. This is a positive correlation and though it is small, it may be of some significance (see discussion on page 39). This would seem to be the case in view of the result obtained by a practical selection of the trees based on seedling size in the nursery as described later in this section.

In general, however, it would seem from the fact that no positive correlation was obtained when seedling trunk area in the nursery was compared with scion trunk area and volume of top of orchard trees, that if any selection is to be made further than that designed to eliminate the variants, it should be based on budling size in the nursery. This is in view of the fact that there is a small but significant positive correlation of the scion trunk area of the budlings with all characters measured in the orchard trees, namely, size of trunk, volume of top, and yield.

Results Obtained by Selection of Seedlings.--In order to obtain more direct information as to the value of any selection other than the elimination of the variants, it was decided to make an actual selection based on size of seedlings just before they were budded, and on 1-year-old budlings, and to determine the results produced. The only population on which the data necessary for testing such a selection is now available is that from the experiment described on pages 23 to 53 of this paper. This population after the elimination of the small seedlings at the seed bed and of all variants, contains 346 trees on which full records have been made. A selection can thus be made of these trees on the basis of the diameter of the seedling rootstocks just before the budding. A segregation of the trees was thus made into three classes, namely, first or large grade, containing all trees of which the seedling trunks at time of budding had a diameter of $2.2 \mathrm{~cm}$ or over; second or medium grade, containing all trees with seedling trunk diameters of $2.1 \mathrm{~cm}$ (this is the modal class); and third or small grade, containing all trees with seedling 
trunk diameters of $2.0 \mathrm{~cm}$ or less. ${ }^{15}$ This segregation gave 109 trees, or 31.5 per cent, in the small or third grade; 73 trees, or 21.1 per cent, in the medium or second grade; and 164 trees, or 47.4 per cent, in the large or first grade.

The yields for the 5-year period during the time when the orchard trees were 4 to 8 years of age, were segregated into the above three classes, and the total 5-year yield and average yield per tree determined for each class. These data are brought together in table 14 .

\section{TABLE 14}

Comparative Yielins Ortained by Segregating Stock Seedlings (After Elimination of Variants) into Large, Medium, and Small Grades*

\begin{tabular}{|c|c|c|c|c|c|c|c|}
\hline Grade & $\begin{array}{c}\text { Diameter } \\
\text { of } \\
\text { seedling } \\
\text { trunk }\end{array}$ & $\begin{array}{c}\text { Number } \\
\text { of } \\
\text { trees }\end{array}$ & $\begin{array}{l}\text { Per cent } \\
\text { of total } \\
\text { popula- } \\
\text { tion }\end{array}$ & $\begin{array}{l}\text { Total } \\
\text { average } \\
\text { yield } \\
\text { per tree }\end{array}$ & \multicolumn{2}{|c|}{$\begin{array}{c}\text { Gain in yield per tree } \\
\text { over third grade }\end{array}$} & $\begin{array}{c}\text { Value } \\
\text { of gain per } \\
\text { tree at } 2 \\
\text { cents per } \\
\text { pound }\end{array}$ \\
\hline Third (small). & $\begin{array}{c}\mathrm{cm} \\
2 \text { or less }\end{array}$ & 109 & $\begin{array}{c}\text { per cent } \\
31.5\end{array}$ & $\begin{array}{c}\text { pounds } \\
238.2\end{array}$ & pounds & per cent & dollars \\
\hline Second (medium) ........................ & 2.1 & 73 & 21.1 & 291.5 & 53.39 & 22.4 & 1.07 \\
\hline First (large). & 2.2 or over & 164 & 47.4 & 295.6 & 57.49 & 24.1 & 1.15 \\
\hline Firsts and seconds combined & 2.1 or over & 237 & 68.5 & 294.4 & 56.22 & 23.6 & 1.12 \\
\hline
\end{tabular}

* Total population 346; mean total yield for 5-year period, 277.18 pounds per tree.

† Over 5-year period.

It will be seen from an examination of table 14 that the thirdgrade trees gave an average yield during the 5-year period of 238.2 pounds per tree; while for the same period, the second-grade trees gave an average yield of 291.5 pounds; and the first-grade trees an average yield of 295.6 pounds per tree. It will be seen that the average yields per tree of the first and second-grade trees do not differ greatly, but that the yield of the third-grade trees is considerably lower. The gain in average yield per tree over the third-grade trees was for the firsts, 57.5 pounds; and for the seconds, 53.4 pounds. In view of the great variation in yields due to environmental and other causes the small difference between the gain found for the firsts and seconds could probably not be considered significant, and any selection discarding the seedlings placed in the second or medium class would probably be meaningless. If the first and second grades are placed together the combined population is 237 , which is 68.5

15 All measurements were made in centimeters and tenths of centimeters, and the segregations made here do not correspond to segregations into class intervals. 
per cent of the total population concerned. This combined population would have an average yield of 294.4 pounds per tree, a gain over the third grade of 56.2 pounds per tree.

Is this gain in average yield per tree sufficiently great to justify a further elimination after the variants are excluded? The elimination of the third-grade seedlings from this population would have meant the elimination of 31.5 per cent of the total number. By sacrificing this proportion of the seedlings there is obtained a gain in average yield per tree of 56.2 pounds, which at 2 cents a pound means a gain of $\$ 1.12$ a tree in value of fruit produced during the early 5-year period of fruiting. This seems sufficient to justify the payment of a fairly high price per tree to insure at least this degree of selection. The value of good seedlings before budding is comparatively small, certainly under normal conditions not over 15 to 20 cents each.

This, perhaps, is a rather confusing result in view of the lack of correlation between seedling size and size of 8-year-old orchard trees, but it should be remembered that there was a small correlation, $+0.135 \pm 0.035$, between area of seedling trunk and total 5 -year yield, which ordinarily would not be considered significant.

Results Obtained by Selection of Budlings.-It is important in determining the most practical method of selection to question whether the main selection might not better be made at the time when the budlings are being dug from the nursery for transplanting, rather than as seedlings before budding, since a few buds possibly will heal poorly. In order to test this idea, the same population of 346 trees after the elimination of the variants, was subjected to a selection based on the size of the 1-year-old budlings as indicated by trunk diameter 2 inches above the bud union. Here, as in the preceding case, a segregation of the trees was made into three classes, namely, large or first-grade trees, containing all trees the scion trunks of which at 1 year of age had a diameter of $1.9 \mathrm{~cm}$ or more; medium or second grade, containing all trees with a scion diameter of $1.8 \mathrm{~cm}$, the modal class; and small or third grade, containing all trees with a scion diameter of $1.7 \mathrm{~cm}$ or less. This segregation gave 104 trees, or 30.1 per cent, in the small or third grade; 69 trees, or 19.9 per cent, in the medium or second grade; and 173 trees, or 50.0 per cent, in the large or first grade.

The total yields per tree for the 5-year period, when the orchard trees were 4 to 8 years of age, were segregated according to these 
three classes and the total 5-year yield and average yield per tree determined for each class. These data are brought together in table 15 .

TABLE 15

Comparison of Yields Obtained by Shgregating Budlings (Afrer Elimination of Those on Variant Seedling Stocks) in'to Large, Medium, and SMall Grades*

\begin{tabular}{|c|c|c|c|c|c|c|c|}
\hline Grade & $\begin{array}{c}\text { Diameter } \\
\text { of } \\
\text { scion } \\
\text { trunk }\end{array}$ & $\begin{array}{c}\text { Number } \\
\text { of } \\
\text { trees }\end{array}$ & $\begin{array}{l}\text { Per cent } \\
\text { of total } \\
\text { popula- } \\
\text { tion }\end{array}$ & $\begin{array}{l}\text { Average } \\
\text { yield } \\
\text { per tree }\end{array}$ & $\begin{array}{r}\text { Gain in y } \\
\text { over th }\end{array}$ & $\begin{array}{l}\text { ld per tree } \\
\text { d grade }\end{array}$ & $\begin{array}{c}\text { Value } \\
\text { of gain per } \\
\text { tree at } 2 \\
\text { cents per } \\
\text { pound } \dagger\end{array}$ \\
\hline Third (small). & $\begin{array}{c}\mathrm{cm} \\
1.7 \text { or less }\end{array}$ & 104 & $\begin{array}{l}\text { per cent } \\
30.1\end{array}$ & $\begin{array}{c}\text { pounds } \\
243.7\end{array}$ & pounds & per cent & $\begin{array}{l}\text { dollars } \\
. . . . . . . . . . .\end{array}$ \\
\hline Second (medium). & 1.8 & 69 & 19.9 & 270.0 & 26.35 & 10.8 & 0.53 \\
\hline First (large) & 1.9 or over & 173 & 50.0 & 299.1 & 55.47 & 228 & 1.11 \\
\hline Firsts and seconds combined & 1.8 or over & 242 & 69.9 & 290.8 & 47.17 & 19.4 & 0.94 \\
\hline
\end{tabular}

* Total population 346 ; mean total yield for 5 -year period. 277.18 pounds per tree.

† Over 5-year period.

A Comparison of Seedling and Budling Selection.--It will be seen from an examination of table 15 and a comparison of the data with those in table 14 that the budling selection is apparently slightly inferior in results to that obtained by the seedling selection. In the third-grade class of small trees presumably to be discarded there are by the budling selection 104 trees with an average yield of 243.7 pounds per tree against 109 with an average yield of only 238.2 pounds per tree when based on a seedling selection. The seedling selection has thus eliminated 5 more trees and the average yield of the whole lot is 5.5 pounds per tree less than the average yield of the 104 trees discarded by the budling selection. The average yield of the second-grade trees for the budling selection is 270.0 pounds per tree as compared to 291.5 for those of the seedling selection of the same grade. For the first-grade trees of the budling selection, however, the yield is 299.1 pounds per tree in comparison with 295.6 for the first-grade large trees of the seedling selection.

If one is to make a very severe selection and weed out both small and medium-sized trees, the budling selection would give a group of trees much reduced in number but with a higher average 5-year yield than those of the same grade of the seedling selection. Even with this severe selection, however, the gain in yield of the first-grade budling's over that of the third-grade budlings is smaller than the gain between the corresponding grades in the seedling selection. If only the first-grade trees of the budling selection were preserved, 
there would be discarded 173 budded trees of salable age. This severe selection would be very expensive.

The careful consideration of these figures and the entire data, it seems to the writer, points rather strongly to the conclusion that with this population a selection of the seedlings just preceding the budding to eliminate approximately 109 of the smallest, or about 31.5 per cent of the total number, was the better method of selection to pursue, and greatly reduced the cost involved in making the selection.

The following further notes on this selection will serve to strengthen this conclusion. The total 5-year yields of these trees varied from 14 pounds per tree to 484 pounds per tree. Choosing arbitrarily 200 pounds per tree as a fair yield and examining the data, the following results are obtained:

1. Good plants, yielding 200 pounds or over, that would be lost by seedling selection but saved by budling selection-26.

2. Good plants, yielding 200 pounds or over, that would be lost by budling selection but saved by seedling selection-28.

3. Poor plants, yielding less than 200 pounds, that would be retained by seedling selection but eliminated by budling selection-8.

4. Poor plants, yielding less than 200 pounds, that would be retained by budling selection but eliminated by seedling selection-17.

It will be clearly recognized that data obtained from a population of 346 trees cannot be considered as conclusive, but this number of trees carefully handled and accurately graded should furnish valuable suggestions. Data have been presented from a similar and much larger population of 1,506 trees, with variants excluded, showing that the correlation of size of budling with size and yield of orchard trees was practically the same as with this population of 346 trees.

It will be remembered that the comparison of seedling size in the nursery with the size of 8-year-old trees gave a very small but not significant negative correlation, indicating that no consistent and sustained relation exists; and yet in carrying out the selection based on seedling size, a fairly satisfactory result was obtained which was rather better than a similar selection based on size of budlings where a small positive correlation was shown to exist regularly. There was, however, a strong correlation between seedling size and budling size, and a small positive correlation between seedling size and yield during the first 5-year period. It is, therefore, evident that the benefit derived from discarding the small seedlings is maintained sufficiently long to result in a financial return that justifies the selection. 
If the policy suggested by the results just outlined is followed, and the main selection in the nursery is made just previous to budding, then the further question is suggested as to whether any selection of the budlings is desirable. Such a selection would naturally be made at the time of digging the budlings and would most naturally be based on the size of the budling trunk. The population of 346 trees can be subjected to this further experimental selection. The selection of the seedlings in the nursery just before budding eliminated 109 seedlings of the third grade and there thus remains a total of 237 budlings ready to transplant to the orchard. If the same basis of segregation as that in table 14 is now used with these 237 budlings, placing in a third grade for discarding all of those with a diameter of scion trunk of $1.7 \mathrm{~cm}$ or less, 39 budlings would be discarded, and the recorded total 5 -year yields of these show that 18 of them were below the mean yield of the modal class (260 to 279 pounds), and 19 above the modal class, with 2 in the modal class. The average 5-year yield of the 39 trees that would be discarded is 261.3 pounds, which is only slightly below the average for the whole population exclusive of variants. A careful examination of the whole history of these 39 trees does not indicate any means by which the few low-yielding trees could have been segregated from the good ones. All excepting possibly 2 or 3, are now of comparatively normal size and their low yields are probably due to environmental causes. It would seem, therefore, that it may be safely concluded that after a selection of seedlings as indicated, the only selection to be exercised among the budlings before they are dug from the nursery should be designed to eliminate the few very smallest ones that have not grown well and are too small to transplant safely.

The case relative to methods of nursery selection as indicated by these studies may be summarized as follows:

1. The results obtained have clearly demonstrated the importance of eliminating all variant types from among the seedlings to be used as rootstocks. The selection to accomplish this, judging from the results obtained, probably should be made both by discarding the small seedlings at the seed bed, and the small and off-type, variant seedlings in the nursery just before budding.

2. It would seem that after the elimination of the variants, the seedlings should be subjected to a further selection to eliminate the small ones to the extent of possibly one-third of the total number remaining. This is based on the fact that the experimental population after the elimination of the variants gave a small, but possibly 
significant, correlation between seedling size and total 5-year yield and also that the elimination of the small seedlings from the population remaining after the variants were discarded resulted in an increased average yield for the first five years of bearing.

In view of the fact that the elimination of the small seedlings and budlings cannot be injurious even if no permanent improvement is achieved, and in view of the fact that the gain in yield during the first few years will probably pay for the cost of the selection, it seems evident that the safest and best policy to pursue is to practice a severe nursary selection. This will insure the elimination of the variants and probably will give a better yield for the first few years. It will probably also insure more uniform trees and a better yield during the whole life of the orchard.

The Influence of Selection Within Apogamic Progenies.-Under "Variation, Apogamy, and Polyembryony in Citrus" (pages 6-15), the types of variation with which this study is concerned were discussed in some detail, as was also the relation of apogamy to the problem of securing citrus stocks of uniform genetic constitution. In the experimental populations studied it has been shown that the most important step in the methods of selection suggested is the elimination of the variants. It has also been shown that the seedlings remaining after the variants are excluded, may be considered to be almost wholly of apogamic origin and thus, if the seeds came from the same mother parent or clon, to possess the same genetic constitution.

In view of the investigations of Johannsen and many others on selection within pure lines, where apparently no significant advance has been obtained, unless there occurred a change of type (mutation), selection within a genetically homogeneous apogamic progeny might be thought to hold little promise.

The investigations on the effectiveness of selection within pure lines, however, so far as the writer is informed, have been directed wholly toward the discovery of whether a change could be induced which would have permanent genetic significance. The investigations, furthermore, have all been with very short-lived plants and animals and never with long-lived perennial trees. It would seem to be entirely reasonable to assume that the selection of the largest seedlings within an exclusively apogamic population or of the largest nursery plants within a single clon might result in a distinct improvement in the size of tree and quantity of the crop produced during a part or all of the life of the trees, and yet not indicate any change of the type that could be considered of genetic significance. 
The evidence from the experiments described in this paper indicates that when dealing with populations from which all variants that could be detected had been eliminated and which were thus supposedly of nearly pure apogamic origin, there was still a considerable range of variation exhibited as indicated by area of cross section of trunk, volume of top, and average yield. The evidence seems also to indicate rather strongly that the elimination from the homogeneous apogamic population in the nursery of the smaller seedlings and smaller budlings tends to increase the size and yield of the orchard trees propagated on those remaining. The increase in yield during the first 8 years from such selected trees in one experiment was found to be sufficient to cover the expense involved in making the selection.

There is thus apparently an advantage possessed by the seedlings and budlings that are large while growing in the nursery which is carried over when they are transplanted into the orchard and persists for a considerable period, at least long enough to give a larger crop of fruit during the first 8 years. There is no evidence available to indicate definitely how long this superiority of the population propagated on the selected stocks will be maintained.

If a selection in the nursery to eliminate the small seedlings and budlings is effective and of practical value in an apogamic progeny where the genetic constitution of the mother is maintained, it should be equally effective with stocks reproduced by cuttings, slips, or layers. Evidence confirming this is furnished by the results obtained by Bioletti (1926) in an experiment testing the effect of size and quality of rootings (rooted cuttings) of the grape. The influence was very marked during the first three seasons in the vineyard, was noticeable in the fourth year, but had largely disappeared by the end of the fifth year. He states:

The first crop of the vines [during the third season] from the strongest 25 per cent of the rootings was about 50 per cent larger than the first crop of the vines from the weakest 25 per cent. This difference was in great part reversed by the second crop and there was little difference in the third crop.

The advantage of the strongest rootings was in reaching nearly full bearing the third season instead of the fourth as with the weaker rootings. The poorest rootings (used in this experiment) were all equal to what are usually considered No. 1 quality. With more imperfect rootings such as are very commonly planted, the difference would undoubtedly have been greater.

Although the evidence with citrus trees presented in this paper is not sufficient to justify a final conclusion, it seems to indicate that with perennial fruit trees an improvement will result from a selection, among an apogamic or clonal progeny, of stock plants of superior 
size and vigor. This improvement can probably be explained as due to the long hold-over influence of a more favorable start, which influences the plant during a considerable portion of its life cycle, and not to any change of genetic nature caused or stimulated by the selection.

Apparently the general principle involved here is the same as that concerned in the production of larger yields by the use of large seeds after an elimination of the small ones. Markedly increased yields obtained by such seed segregations have been reported for almost all annual crops propagated by seeds.

Blackman (1919) has pointed out that the stored nutrition carried by the seed or plant body may be considered as the capital investment with which the young plant starts growth and that the growth rate of the plant may be likened to the interest rate which is compounded very frequently. If the growth rate (interest) is the same in two plants, that one starting with the largest quantity of stored material (capital) may be expected to remain the largest if grown under uniform conditions.

With perennial trees having the same growth rate and grown under uniform conditions those that are largest in the beginning should theoretically remain the largest until the trees approach mature age and size when growth rate is equalled by decay.

\section{METHOD OF NURSERY SELECTION SUGGESTED}

Based on the data and results outlined in this paper the following methods of nursery selection are suggested:

Seed Bed Selection.-When the seedlings are dug from the seed bed discard the smallest seedlings to the extent of about one-fourth of the whole population, or 25 per cent. Discard at this time all malformed seedlings such as extreme cases of "goose neck" or "bench root."

Twenty-five per cent is an arbitrarily chosen quantity. This is, however, rather more severe than the ordinary selection made at the seed bed and will eliminate a considerable proportion of the variant types.

Nursery Selection.-When the seedlings growing in the nursery have reached the size and age for budding, go over them carefully and cut out all plants differing sufficiently from the standard or normal type of the stock to be recognized as distinct and peculiar in any character. This elimination should be irrespective of size. After this elimination of variants, the small seedlings should be cut out and dis- 
carded to the extent of from 25 to 30 per cent of the entire remaining population.

After this elimination has been made the entire remaining population may be budded and safely considered as propagated on good, uniform, highly selected stocks. As the seedlings up to this time, previous to budding, have little value, the carrying out of this elimination does not entail very great financial loss.

Budling Selection.-Some buds do not heal well or are defective and do not give vigorous good trees. Such small and inferior budlings should be cut out and discarded before the budlings are dug for orchard planting. With good buds and selected large stocks the elimination at this time will be very slight, probably not over 1 to 5 per cent.

\section{SUMMARY}

The investigations discussed in this paper are concerned with: first, the influence that variable seedlings used as rootstocks exercise on the size and yield of orchard trees; and second, the determination, if possible, of a basis of selection that may be used in the improvement of citrus nursery stock.

Citrus seedlings, of the species and varieties most commonly used for rootstocks, exhibit a wide range of variation. In any lot of seedlings grown from seed of the same variety and from the same source, the great majority usually are of the same general type, but from 5 to 40 per cent of them are highly variable types which apparently differ in genetic constitution from the prevailing type and from each other.

The evidence available indicates that the seedlings of the prevailing type originate from apogamic embroyos and are thus, presumably, of the same genetic constitution as the seed parent or parents. Some citrus varieties exhibit a very high degree of apogamy (80 to 100 per cent), and by the use of seeds from such sorts, large lots of seedlings almost uniform genetically and of the same type can be easily obtained for use as stocks.

The seedlings of variable types which are present in small numbers in all lots of citrus seedlings (except those of sorts which are 100 per cent apogamic) are here termed variants. They are probably developed from the normally produced sexual embryos mainly by self-fertilization, but to some extent by cross-fertilization. The seedlings of variant types are usually small and lacking in vigor, and when used as stocks 
are found almost invariably to produce orchard trees exhibiting some degree of dwarfing.

In one experiment, large, medium, and small budlings (nursery trees) of Washington Navel and Valencia oranges and of Marsh grapefruit, all propagated on sweet-orange stocks, were grown side by side for comparison. After 11 years in the orchard under approximately uniform conditions, the correlations of budling trunk area with the trunk area, volume of top, and total 6-year yields of the orchard trees in all but 1 of the 9 plots were positive and significant.

The following results were obtained from a study of another carefully planned experiment with 389 trees of Washington Navel orange on sour-orange stocks. Each tree was observed from the seed-bed stage through the nursery and for 8 years after planting in an experimental orchard.

1. The seedlings, when dug from the nursery, and after the elimination of the very small ones, were segregated into two grades, large and small, which were kept separate in the nursery. Among these there were 43 seedlings of variant types which later were found to cause marked dwarfing of the orchard trees budded on them and were very unsatisfactory. Seventy-seven per cent of these variant types were among the seedlings graded as small at the seed bed.

2. These variant seedling types were propagated on sour-orange and Rough-lemon stocks, one tree on each stock, and were found to maintain their marked varietal characteristics unchanged by the influence of the two stocks. The stock influence was limited apparently to quantitative characters only, such as differences in size.

3. The size of nursery seedlings, as shown by area of trunk cross section correlated with the size of budlings and 8-year-old orchard trees, gave coefficients respectively of $+0.736 \pm 0.016$, and +0.437 \pm 0.028 . These fairly strong correlations were influenced to a considerable extent by variants, as a result of their dwarfing influence.

4. When the population, exclusive of variants, was used and size of seedlings compared with the size of budlings and with 2,6 , and 8-year-old orchard trees, the correlations were $+0.549 \pm 0.026$, $+0.125 \pm 0.036,+0.010 \pm 0.036$, and $-0.021 \pm 0.037$ respectively, indicating that there was a temporary relation between the size of selected seedlings and the size of trees after planting in the orchard.

5. The size of nursery seedlings, exclusive of variants, compared with the top volume of 8-year-old trees gave no correlation $(-0.012$ \pm 0.036 ), but it is possibly significant that with a total 5 -year yield per tree a positive correlation of $+0.135 \pm 0.035$ was obtained. 
6. The size of 1-year-old budlings compared with the size of 8 -year-old orchard trees gave a correlation of $+0.622 \pm 0.021$ for the entire population; and for the population exclusive of variants at 2,6 , and 8 years old gave correlations respectively of $+0.358 \pm 0.032$, $+0.170 \pm 0.036$, and $+0.182 \pm 0.034$.

7. Size of budlings compared with 5-year yields gave for the entire population a correlation of $+0.517 \pm 0.025$, and for the same population exclusive of variants $+0.233 \pm 0.034$. Thus there was a general tendency for the large budlings to produce large, high-yielding trees, and for the small budlings to produce small, low-yielding trees.

8. The coefficients of variability for size of tree gradually decreased as the trees grew older.

9. The comparison of trunk area of budlings with top volume of 8-year-old trees gave for the entire population a correlation of $+0.598 \pm 0.022$ and for the population exclusive of variants, +0.202 \pm 0.035 , thus corresponding very closely with the results obtained when the trunk areas of budlings and of 8-year-old trees are correlated, and also with the correlation of trunk area of budlings with 5 -year yields.

10. The close similarity of the statistical constants obtained when different measures were used (such as area of trunk, volume of top, and yields of fruit) are interpreted as indicating the reliability of the results.

11. There was a very close relation between the size of the trunk and the size of the top at the same period of development, as shown by the high correlations between trunk area in 1929 and top volume in 1930 , which was $+0.923 \pm 0.006$ for the entire population; and $+0.817 \pm 0.013$ for the population exclusive of variants.

12. While the budling trunk area for the entire population exclusive of variants compared with the trunk area of 8-year-old orchard trees gave a correlation of only $+0.182 \pm 0.034$, the budlings with 2 -year-old orchard trees gave a correlation of $+0.358 \pm 0.032 ; 2$-year trees with 6-year trees, $+0.618 \pm 0.023$; and 6 -year trees with 8-year trees, $+0.781 \pm 0.014$. These rapidly increasing degrees of correlation for interperiods are interpreted as being caused probably by the cumulative influence of variations in soils rather than by variations in the rootstocks.

With this population (containing, after the elimination of the variants, 346 trees supposedly of apogamic origin and thus of nearly uniform genetic constitution) a segregation of the seedlings on the 
basis of the recorded diameter at the time of budding gave 31.5 per cent of $2.0 \mathrm{~cm}$, or less in diameter, and 68.5 per cent of $2.1 \mathrm{~cm}$, or more in diameter. The orchard trees grown on the large seedlings gave an average 5-year yield of 56.22 pounds per tree more than the trees on the seedlings of the small group, an average gain per tree of 23.6 per cent.

A similar segregation of the same population on the basis of the recorded diameter of the budlings at the time of transplanting gave 30.1 per cent budlings of $1.7 \mathrm{~cm}$ or less in diameter, and 69.9 per cent of $1.8 \mathrm{~cm}$ or more in diameter. The orchard trees grown from the large budlings gave an average 5-year yield of 47.17 pounds per tree more than the trees of the small budling group, an average gain per tree of 19.4 per cent. These results indicate that a selection of the seedlings is as effective as a selection of the budlings; and it is much less expensive.

In a population of 1,506 Washington Navel trees on sweet-orange stocks from which all small budlings (and thus probably all markedly variant rootstocks) had been eliminated, the correlations between trunk area of the young trees and trunk area and total yields of 9-yearold trees were respectively $+0.158 \pm 0.017$, and $+0.229 \pm 0.016$. There is a noticeable and significant similarity between these correlations from Washington Navels on sweet-orange stocks and those from Washington Navels on sour-orange stocks.

In a commercial orchard where nursery trees were segregated at the time of planting into groups of large, medium, and small trees and planted separately in adjoining parts of the same orchard, the groups retained their relative differences in size up to the age of 7 years.

The evidence from all experiments and observations indicates that in general with entire populations, small seedlings and small budlings tend to produce small, low-yielding orchard trees; and that large seedlings and large budlings tend to produce comparatively large, high-yielding orchard trees.

The evidence clearly indicates that the most important factor in the improvement of citrus nursery stock is the elimination of the variant seedlings that were found almost uniformly to produce weak and dwarfed orchard trees.

The segregation of the seedlings when they were dug from the seed bed into first and second grades (large and small), was found effective only to the extent that it served to isolate with the seconds, 81.18 per cent of the variants. This proportion of the variants, 
therefore, could have been destroyed by discarding all of the seconds, which comprised 47.77 per cent of the total population transplanted from the seed bed. The normal seedlings anong those chosen as seconds at the seed bed gave orchard trees as satisfactory as the normal trees of the first grade.

The experiment indicates that the elimination of the variants can be accomplished, probably with the least loss, by a moderate culling of the small seedlings at the seed bed, and by the careful roguing and destruction of all variants and small seedlings in the nursery just prior to the budding.

The evidence also indicates that a selection based on the size of the seedlings or of the budlings remaining after the elimination of the variants, would result in a small but valuable improvement. This improvement is probably due to the long hold-over influence of a more favorable and better start which affects the plant during a considerable portion of its life, and not to any change of genetic nature caused or stimulated by the selection.

A plan of nursery selection is suggested which is based on the results of these studies and is designed for use in commercial nurseries.

\section{ACKNOWLEDGMENTS}

For assistance in taking and recording field notes in connection with these experiments the author wishes to express his thanks especially to Robert McBride, Assistant Superintendent of Cultivations (deceased), and to Ralph G. La Rue, Superintendent of Cultivations in the Citrus Experiment Station. Thanks are also due especially to H. F. Stevens and E. R. Parker, both of the Citrus Experiment Station Staff, for assistance and suggestions in connection with the statistical work involved. The statistical calculations have all been made by Mr. Stevens working under the writer's direction.

Much of the work on one of the major experiments was carried on for several years by J. T. Barrett and due acknowledgment was made under the discussion of that particular experiment.

The writer wishes also to express his appreciation of the helpful criticisms and suggestions made during the preparation of this manuscript by Professor R. D. Anthony of the Pennsylvania Agricultural Experiment Station, State College, Pennsylvania. 


\section{BIBLIOGRAPHY ${ }^{16}$}

Amos, J., R. G. Hatton, T. N. Hoblyn, and R. C. Knight.

1930. The effect of scion on root. II. Stem worked apples. Jour. Pomol. and Hort. Sci. 8:248-258.

Batchelor, L. D., E. R. Parker, and Robert McBride.

1928. Studies preliminary to the establishment of a series of fertilizer trials in a bearing citrus grove. California Agr. Exp. Sta. Bul. 451:1-49.

Bioletti, Fredric T.

1926. Selection of planting stock for vineyards. Hilgardia 2:1-23.

BLACKMAN, V. H.

1919. The compound interest law and plant growth. Ann. Bot. 33:353-360.

Bonns, W. W., and W. M. Mertz.

1916. Experiments with stocks for citrus. California Agr. Exp. Sta. Bul. 267:275-301.

BROWN, W. ROBERTSON.

1920. The orange: a trial of stocks at Peshawar. Agr. Research Inst. Pusa, India Bul. 93:1-6.

Burkholder, C. L., and Laurenz Green.

1929. Influence of size of mahaleb seedlings on nursery grades. Amer. Soc. Hort. Sci. Proc. 26:96-97.

Collison, R. C., and J. D. Harlan.

1930. Variability and size relations in apple trees. New York State Agr. Exp. Sta. Tech. Bul. 164:1-38.

Frost, Howard B.

1926. Polyembryony, heterozygosis and chimeras in eitrus. Hilgardia 1: 365-402.

HaAs, A. R. C., and F. F. Halma.

1929. Chemical relationship between seion and stock in citrus. Plant Physiology 4:113-121.

Hatton, R. G.

1917. Paradise apple stocks. Jour. Royal Hort. Soc. 42:361-399.

MilLs, J. W.

1902. Citrus fruit culture. California Agr. Exp. Sta. Bul. 138:1-46.

OPFENHEIM, J. D.

1931. The selection of citrus trees, its importance and problems. Hadar [Palestine Citrograph] 3:274-276; and 4:4-7.

OSAWA, I.

1912. Cytological and experimental studies in eitrus. Jour. Col. Agr. Imp. Univ. Tokyo 4:83-116.

16 Some papers not specifically eited in this paper are included. 
PARKer, E. R., and L. D. Batchelor.

1932. Variations in the yields of fruit trees in relation to the planning of future experiments. Hilgardia. (In press.)

ROBERTS, R. H.

1929. Some stock and scion observations on apple trees. Wisconsin Agr. Exp. Sta. Res. Bul. 94:1-39.

SAX, KARL.

1924. Nursery stock investigations. Amer. Soc. Hort. Sci. Proc. 21:310-312.

1928. Bud and root selection in the apple. Maine Agr. Exp. Sta. Bul. $344: 21-32$.

Sax, KarL, and John W. Gowen.

1922. The relation of tree type to productivity in the apple. Maine Agr. Exp. Sta. Bul. 305:1-20.

1923. The place of stocks in the propagation of clonal varieties of apples. Genetics 8:458-465.

Shamel, A. D., L. B. ScotT, and C. S. Pomeroy.

1918. Citrus-fruit improvement, a study of bud variation in the Washington Navel orange. U. S. Dept. Agr. Bul. 623:1-146.

STRASBURGer, E.

1878. Über Polyembryonie. Jenaische Zeitsch. f. Naturwiss. 12:654.

SWarbrick, 'Thomas, and R. H. Roberts.

1927. The relation of scion variety to character of root growth in apple trees. Wisconsin Agr. Exp. Sta. Res. Bul. 78:1-23.

TABER, G. L.

1904. Fruitfulness of the orange on Trifoliate, sweet and sour. Quoted in: Hume, H. Harold, Citrus fruits and their culture. pp. 209-218. Jacksonville, Florida.

TANAKa, YUICHIRo.

1931. The inter-relation between scion and stock in citrus, with special reference to the influence of scion on stock. Studia Citrologica [Edited by Tanaka Citrus Exp. Sta.] 4:213-227.

Toxopeus, H. J.

1930. De polyembryonie von citrus en haar beteekens voor de cultuur. Dep. Landbouw. Algemeen Proefst. Korte Meded No. 8:1-15. Also in Landbouw (Buitenzorg) Jrg. 6(4):1930-31.

Van Deman, H. E.

1891. Relative merit of the various stocks for the orange. U. S. Dept. Agr. Div. Pomology Bul. 4:1-25.

VYVYAN, M. C.

1930. The effect of scion on root. III. Comparison of stem and root-worked trees. Jour. Pomol. and Hort. Sci. 8:259-282.

WeBBER, H. J.

1900. Complications in citrus hybridization caused by polyembryony. Science n.s. 11:308-309.

$1900 a$. Work of the United States Department of Agriculture on plant hybridization. Jour. Roy. Hort. Soc. [London] 24:128-138.

1905. Notes on citrus hybrids. Amer. Breeders' Assoc. Ann. Rept. 1:78-86. 
1919. Influence of character of stock on citrus tree growth. California Citrograph 5:35.

1920. Selection of stocks in citrus propagation. California Agr. Exp. Sta. Bul. 317:267-301.

1920a. The improvement of root-stocks used in fruit propagation. Jour. Heredity 11:291-299.

1922. The relation of stocks to scions with special reference to citrus. Amer. Soc. Hort. Sci. Proc. 19:129-139.

1922a. Citrus root-stock problems. California Citrograph 7:391, 408-411.

1926. The lemon root-stock problem. California Citrograph 11:374, 398-401. 1926a. Root-stock reactions as indicating the degree of congeniality. Amer. Soc. Hort. Sci. Proc. 23:30-36.

1928. The citrus root-stock problem in California. California Citrograph 14:50, 74-76.

1930. The basis of selection in the improvement of citrus nursery stock. Amer. Soc. Hort. Sci. Proc. 27:114-119.

WebBer, H. J., and J. T. BarretT.

1930. Root-stock influence in citrus. Proc. IX Internatl. Hort. Congress, London, pp. 358-373.

WebBer, H. J., and W. T. Swingle.

1905. New citrus creations of the Department of Agriculture. U. S. Dept. Agr. Yearbook 1904:221-240.

WoGLuM, R. S.

1909. Fumigation investigations in California. U. S. Dept. Agr. Bureau Ent. Bul. 79:1-73. 
